\title{
ACTUALIDAD LEGISLATIVA
}

Jaime Alcalde Silva

Juan Luis Goldenberg Serrano

Profesores asociados de Derecho Privado

Pontificia Universidad Católica de Chile

ALGUNAS OBSERVACIONES PRELIMINARES RESPECTO DEL PROYECTO DE LEY QUE MODI-

FICA EL SISTEMA REGISTRAL Y NOTARIAL EN SUS ASPECTOS ORGÁNICOS Y FUNCIONALES

\section{INTRODUCCIÓN}

El 11 de septiembre de 2018 fue ingresado a la Cámara de Diputados un proyecto de ley que modifica el sistema registral y notarial en sus aspectos orgánicos y funcionales (en adelante, el Proyecto), el cual fue presentado a través del Mensaje presidencial n. ${ }^{\circ} 115-366$ (Boletín n. ${ }^{\circ}$ 12092-07). Esta iniciativa es la reacción del Poder Ejecutivo al "Estudio de mercado sobre notarios" (EM022017) hecho público por la Fiscalía Nacional Económica el 31 de julio del mismo año, donde se detectan problemas de competencia en el funcionamiento de las notarías y en la prestación de servicios por parte de ellas.

Las presentes observaciones sobre ese Proyecto están estructuradas en tres partes:

II algunas prevenciones generales de técnica legislativa;

III las cuestiones institucionales relativas al oficio de notario y conservador;

IV los aspectos que tienen relación con la digitalización de los registros conservatorios y la creación de un repositorio digital a cargo del Servicio de Registro Civil e Identificación, y

$\mathrm{V}$ la escasa recepción de los principios propios de la función registral y la creación de un folio real.

Queda fuera el análisis pormenorizado de las cuestiones relativas al ejercicio de la función notarial o al nuevo oficio de fedatarios, las cuales serán tratadas de forma referencial.

\section{Algunas Cuestiones PRevias de téCniCA legislativa}

La lectura del Proyecto sugiere algunas consideraciones generales relacionadas con la técnica legislativa empleada. Ellas tienen relación con

1) la necesidad de un tratamiento diferenciado entre notarios y conservadores; 
2) la exclusión de los principios propios del mercado;

3) la necesidad de un tratamiento armónico de los distintos conservadores existentes;

4) el regreso a un sistema registral coherente a partir de la distinción fundamental entre registros de hechos y registros de derechos y

5) la creación de la figura de los fedatarios y el impulso de desnotarización.

\section{La necesidad de un tratamiento diferenciado entre notarios y conservadores}

Es cierto que el COT trata dentro de una misma categoría a los notarios, conservadores y archiveros, pues todos ellos son auxiliares de la administración de justicia (título XI del COT) y forman parte de la segunda serie del escalafón secundario (art. 269 del COT), que pertenece al escalafón general de antigüedad del Poder Judicial (art. 264 del COT). Sin embargo, esos oficios son muy distintos entre sí y resulta necesario un estudio separado de las reformas que para cada uno de ellos se desea introducir.

Esta diferencia también se hace evidente en el informe de la Fiscalía Nacional Económica, que aborda la situación de los notarios y solo en parte de las ciudades de Santiago y Valparaíso. Pese a que no es aconsejable que el oficio de los auxiliares de la administración de justicia se rija por reglas de puro corte 244 economicista, hay que tener presente que el respaldo del Proyecto descansa sobre dicho informe y ahí no se aborda la cuestión de los conservadores y archiveros, donde la existencia de un oficio único por comuna o agrupación de comunas tiene sentido (arts. 447 y $454 \mathrm{del}$ COT). De hecho, hay ocasiones en que resulta aconsejable propender a una estructura geográfica mayor por razones de economía de escala.

En especial, esto importa para dividir los cargos de conservador y notario, como propone el nuevo art. $450 \mathrm{del} \mathrm{COT.} \mathrm{No} \mathrm{ocurre} \mathrm{lo} \mathrm{mismo} \mathrm{con} \mathrm{la}$ compatibilidad que el art. 454 del COT prevé respecto de los oficios de conservador y archivero, donde la acumulación es facultativa ("el Presidente de la República podrá también disponer que éste [el conservador] ejerza el cargo de archivero"). La redacción debería corregirse en el sentido de propender a que los cargos recaigan en un mismo funcionario, dado que es recomendable que así sea por una razón de costos (la custodia de expedientes y protocolos no resulta rentable para el funcionario que sirve el cargo de manera separada, con excepción de Santiago).

Por cierto, llama la atención la división que se propone respecto del Conservador de Bienes Raíces de Santiago, que será servido en adelante por cuatro oficios, cada uno con tres funcionarios (art. 449 del COT), sin que se precise el modo en que se efectuará esa división y manteniendo injustificadamente el absurdo de persistir con la segregación de los registros, lo que agudiza al mismo tiempo la discriminación en el tratamiento legal entre dicho conservador y los del resto del país. Cumple recordar que en la actualidad el Conservador de 
Bienes Raíces de Santiago se divide por ley (en virtud del citado art. 449 del COT), y los demás por simple decreto. En este sentido, el Proyecto hace más aberrante la situación, dado que, por una parte, divide por ley el Conservador de Bienes Raíces de Santiago (insistiendo en el criterio discutible con que hoy lo hace ${ }^{1}$ y, por otra, parece someterlo, también, al régimen general de división por decreto (de lo contrario, se produciría el problema recién apuntado respecto de la manera concreta de división), lo que en todo caso no aparece resuelto en el propio Proyecto. La pregunta que surge de esta forma de división es si, una vez dividido por ley el Conservador de Santiago, también podrá ser dividido por decreto con posterioridad y, de ser así, si debe mantenerse la segregación de sus respectivos registros. Lo racional es dividir este Conservador por comunas, como se hizo cuando en el año 1955 se escindió el Conservador de San Miguel

\section{La exclusión de los principios propios del mercado}

El hecho de tratarse de auxiliares de la administración de justicia hace que la lógica propia del mercado resulte inaplicable, puesto que se trata de personas que prestan un servicio que es, por su propia naturaleza, de carácter público. Que se trate de personas que ordenan su labor a la ayuda y apoyo de los tribunales de justicia significa que participan por accesoriedad de la función que desempeñan y que tiene relación con el ejercicio de la jurisdicción. De ahí que resulte alejado de su realidad jurídica el informe de la Fiscalía Nacional Económica, que aborda la cuestión desde la perspectiva de un mercado y las deficiencias que presenta en cuanto a su competitividad. La razón proviene de que se trata de un complemento de la función judicial y de una actividad pública regulada, de manera que la existencia de un cierto monopolio resulta justificada. Aplicar la lógica economicista en esta materia supondría, por ejemplo, concluir que no hay suficiente competencia respecto de los tribunales o, en otro ámbito, en lo que se refiere a la prestación del servicio de transporte público. En esos casos, la estricta observancia de la competencia puede resultar perjudicial y sesgada.

\section{La necesidad de un tratamiento armónico de los distintos conservadores existentes}

Es cierto también que el registro conservatorio más importante es el relativo a los bienes raíces, tanto por su historia (fue el primero en ser establecido) como por su regulación (se rige por el reglamento de mayor extensión), por lo que resulta natural que el Proyecto solo se refiera a él. Sin embargo, el art. 446 del COT menciona como parte del mismo oficio a los conservadores a cargo de otros registros, y esa norma no es objeto de modificación por parte

\footnotetext{
${ }^{1}$ La división del oficio en tres funcionarios ya se encuentra en el art. 451 de la versión original del COT.
} 
del Proyecto. Por consiguiente, una regulación coherente y orgánica exige que se busque uniformar los distintos regímenes existentes, permitiendo que los registros cumplan su función propia de registro de derechos, sobre todo cuando el Reglamento del Registro Conservatorio de Bienes Raíces cumple una función supletoria de varios otros registros especiales, como ocurre con el Registro de Comercio (art. $2^{\circ}$ y 40 del RRC), el Conservador de Minas (art. 99 del Código de Minería) o el Registro de Aguas (art. 112 del Código de Aguas).

La ordenación del sistema registral es una tarea pendiente en cualquier sistema jurídico que aspire hacia su modernización. Muchas de las innovaciones que pueden introducirse ni siquiera requieren de una reforma legal y, de hecho, ya están siendo implementadas por algunos conservadores a través de iniciativas de índole tecnológica, tanto de hardware como de software e interconexión electrónica ${ }^{2}$. A fin de cuentas, se trata de incorporar tecnologías de la información al proceso registral, lo que resulta loable y necesario. Sin embargo, ese propósito no debe hacer perder los logros conseguidos en más de ciento sesenta años de funcionamiento del sistema registral chileno, poniendo en riesgo la seguridad de los derechos adquiridos de que dan cuenta esos registros.

\section{El regreso a un sistema registral coherente a partir de la distinción fundamental entre registros de hechos y registros de derechos}

246 El Proyecto desaprovecha la oportunidad para volver a dar coherencia al sistema registral chileno desde una perspectiva orgánica y funcional. Desde hace algunas décadas, las sucesivas reformas introducidas en diversas materias han roto la manera en que deberían conformarse los registros. La tendencia ha sido a desplazar una serie de registros existentes o, bien, de nueva creación al Servicio del Registro Civil e Identificación, el cual se encarga de practicar las anotaciones que correspondan y cuidar de su conservación. Es cierto que entre el Registro Civil y los demás registros existen algunos principios comunes, pero ellos no deben hacer olvidar que subyace una diferencia fundamental: el primero certifica hechos que ocurren durante la vida de una persona y que inciden sobre su estado civil o su propia condición, mientras que el segundo da cuenta de titularidades sobre el objeto registrado. Esto permite calificar los registros en aquellos que dan cuenta de hechos y aquellos que se refieren a derechos. Esta distinción es muy importante, porque permite asignar su correcto sentido a la función que tiene cada registro particular y a la determinación del funcionario que resulta más idóneo para hacerse cargo de él.

Resulta razonable que el Servicio del Registro Civil e Identificación exista para velar "por la constitución legal de la familia" y que su "objeto principal [sea] registrar los actos y hechos vitales que determinen el estado civil de las

\footnotetext{
${ }^{2}$ De momento, son alrededor de veinte los conservadores que están llevando a cabo estas iniciativas de manera voluntaria, desde Arica a Castro. A esto se suma la iniciativa del Conservador Digital.
} 
personas y la identificación de las mismas" (art. $3^{\circ}$ de la Ley n. ${ }^{\circ}$ 19477), puesto que la idea original que existe detrás de su establecimiento es dar cuenta de hechos que han ocurrido: una persona ha nacido (art. $3^{\circ}$ de la Ley n. ${ }^{\circ} 4808$ ), ha muerto (art. $5^{\circ}$ de la Ley n. ${ }^{\circ} 4808$ ), ha cambiado de género (art. 20 de la Ley n. ${ }^{\circ} 21120$ ) o de nombre (art. $3^{\circ}$ de la Ley n. ${ }^{\circ} 17344$ ), se ha casado (art. $4^{\circ}$ de la Ley n. ${ }^{\circ} 4808$ ) o celebrado un acuerdo de unión civil (art. $6^{\circ}$ de la Ley n. ${ }^{\circ}$ 20830), ese matrimonio o acuerdo de unión civil han sido declarados nulos por sentencia judicial (arts. 50 de la Ley n. ${ }^{\circ} 19947$ y 26 de la Ley n. ${ }^{\circ} 20830$ ), dicho matrimonio ha terminado por divorcio (art. 59 de la Ley n. ${ }^{\circ} 19947$ ), se ha alterado el régimen de bienes existente entre los cónyuges (art.o 1723 del CC) o convivientes civiles (art. 15 de la Ley n. ${ }^{\circ} 20830$ ), la persona ha cambiado su filiación (arts. 199 bis y 221 del $C C$ ), etcétera. Se trata de situaciones delimitadas por presupuestos subjetivos y objetivos que hacen que su ocurrencia pueda ser fácilmente constatable. Esto hace que el oficial del Registro Civil sea ministro de fe de dichas situaciones (art. 29 de la Ley n. ${ }^{\circ}$ 1.477), sin que se requiera tener formación jurídica (art. 32 de la Ley n. ${ }^{\circ}$ 19477): el control preventivo que ejerce es mínimo y viene condicionado por la ley a circunstancias objetivas. Pertenecen a esta categoría de registros de hechos los siguientes: de Nacimiento (1884), de Matrimonio (1884) y de Defunción (1884); General de Condenas (1925); de Cédula de Identidad (1943); de Pasaportes (1943); de Profesionales (1981); Nacional de Conductores de Vehículos Motorizados (1985); Nacional de Discapacidad (1994); Nacional de Violencia Intrafamiliar (1994); Especial de Faltas sobre de Consumo y Tráfico de Estupefacientes (1995); de Bancos de Datos Personales a cargo de Organismos Públicos (1999); Nacional de Transporte de Carga Terrestre (2003); Nacional de Posesiones Efectivas (2003); Nacional de Testamentos (2003); Sistema Nacional de Registros de ADN (2004); Nacional de no Donantes (2013) y Especial de Acuerdos de Unión Civil (2015).

De igual forma, resulta razonable el sistema previsto en el art. 446 del COT respecto de los conservadores: ellos son ministros de fe encargados de los registros de derecho que la ley establece, lo que explica que deban ser abogados con méritos comprobados (art. 287 del COT). La calificación profesional exigida se explica por la función de control preventivo (calificación registral) que ejercen, la cual está constituida por todas aquellas precauciones que la ley contempla para el ingreso de un derecho en el registro y luego para sus sucesivos traspasos ${ }^{3}$. De ahí que el respectivo conservador tenga atribuciones para calificar

i) la existencia y estado jurídico del derecho que se le presenta para inscripción y

ii) la congruencia entre la descripción del objeto sobre el que recae el título y los caracteres que presenta en la realidad ${ }^{4}$.

Su cometido no es, por consiguiente, solo fáctico, en el sentido de dar fe

${ }^{3}$ Peñallillo (2019), p. 787.

${ }^{4}$ Ibid. 
que ciertos hechos han ocurrido (por ejemplo, que dos personas han contraído matrimonio en un lugar y momento determinados) o han sido establecidos por otros (por ejemplo, el divorcio mediante una sentencia ejecutoriada dictada por un juez de familia), sino que exige comprometer esa fe pública respecto de la existencia de un derecho y su consiguiente oponibilidad a terceros. Por eso, quien tiene a cargo esta clase de registros goza de una facultad para revisar la legalidad de los títulos que se le presentan, pudiendo rechazar aquellos que aparecen de algún modo como ineficaces (art. 13 del RRCBR).

La ruptura de esta dualidad entre registros de hechos y registros de derechos se produjo en 1985 con la creación del Registro de Vehículos Motorizados, que el art. 39 de la Ley del Tránsito confía al Servicio de Registro Civil e Identificación, el cual estaba hasta entonces confiado al Conservador de Bienes Raíces en calidad de Conservador de Vehículos Motorizado (art. 40 de la Ley n. ${ }^{\circ}$ 15231). No resulta difícil darse cuenta cuál fue la razón que existió para esta decisión: esa clase de bienes está por su propia naturaleza sujeta a un constante cambio locativo, lo que dificulta la comprobación de su inscripción si se rigiese por un sistema territorial como el que existe para los conservadores de bienes raíces (arts. 447-449 del COT). Siendo así, y por ser el Servicio de Registro Civil y de Identificación de alcance nacional, se le confío un registro que da cuenta de titularidades sobre vehículos motorizados (arts. 39 y 41 de la Ley del Tránsito). Con todo, el funcionamiento del sistema es algo diferente del que se observa 248 respecto de la propiedad raíz. Ante todo, porque la constitución del dominio, su transmisión, transferencia y los gravámenes sobre vehículos motorizados se sujetan a las normas que el derecho común establece para los bienes muebles (art. 38 de la Ley del Tránsito), lo cual significa que se aplica a su respecto el art. 684 del $C C$, vale decir, su tradición se puede hacer "significando una de las partes a la otra que le transfiere el dominio, y figurando esta transferencia" de algún modo sensible. La inscripción en el Registro de Vehículos Motorizados constituye una presunción simplemente legal de que el titular de ella es el dueño del bien (art. 44 de la Ley del Tránsito) y sirve para hacer oponibles a tercero los actos que recaigan sobre el mismo (art. 41 de la Ley del Tránsito). Respecto de las inscripciones que se le requieran, el Servicio de Registro Civil ejerce un cierto control preventivo (art. 49 de la Ley del Tránsito), el cual es de carácter formal y atañe a que los títulos que se le presentan cumplan con las menciones mínimas establecidas en el reglamento respectivo (arts. $5^{\circ}$ y 11 del DS 1111/1984, del Ministerio de Justicia).

Algo parecido ocurre con el Registro de Prendas sin Desplazamiento, que también se confía al Servicio de Registro Civil e Identificación (artículo 28 de la LPSD $)^{5}$. Con todo, existe una diferencia con el registro recién referido, puesto que el derecho real de prenda se adquiere, prueba y conserva por la inscripción del contrato de prenda en el Registro de Prendas sin Desplazamiento (art. 25 de la LPSD), teniendo el Servicio de Registro Civil e Identificación

\footnotetext{
${ }^{5}$ La LPSD está contenida en el artículo 14 de la Ley n. ${ }^{\circ} 20190$.
} 
unas supuestas atribuciones de control preventivo respecto de las inscripciones que se le requieran (art. 28 IV de la LPSD), las cuales no son desarrolladas en el reglamento respectivo (DS 722/2010, del Ministerio de Justicia).

La eliminación definitiva de los principios registrales de legalidad se produjo merced a la Ley n. ${ }^{\circ}$ 20659, que simplificó el régimen de constitución, modificación y disolución de las sociedades comerciales mediante la creación de un registro de empresas y sociedades que sustituye tanto la inscripción del extracto en el Registro de Comercio como su publicación en el Diario Oficial $\left(\operatorname{art.} 1^{\circ}\right)$. Este registro es único y consta en un sitio electrónico, donde deben incorporarse las personas jurídicas que se acojan su régimen para los efectos de ser constituidas, modificadas, transformadas, fusionadas, divididas, terminadas, disueltas o migradas, el cual ha de estar actualizado de manera permanente para asegurar la fiel y oportuna publicidad de la información incorporada en él (art. 11 de la Ley n. ${ }^{\circ}$ 20659). La particularidad de este sistema es que el acto de constitución, modificación, transformación, fusión, división o disolución de alguna de las personas jurídicas listadas en el art. $2^{\circ}$ de la Ley n. ${ }^{\circ} 20659$ se satisface con la suscripción de un formulario electrónico (art. $6^{\circ}$ de la Ley n. ${ }^{\circ}$ 20659), el cual se incorpora de forma automática en el Registro a contar de la fecha en que ha sido suscrito por todos los intervinientes (art. 13 de la Ley n. ${ }^{\circ}$ 20659), sea por sí o por un notario que concurra al efecto con su firma electrónica avanzada (art. $9^{\circ}$ de la Ley n. ${ }^{\circ}$ 20659). No hay, en suma, ningún control de legalidad o de calificación registral de la información que se aloja en el sistema más allá de las cuestiones formales que vienen predispuestas en los campos del formulario.

Por lo demás, la cuestión ha interesado incluso a la UNCITRAL/CNUDMI, cuyo "Grupo de Trabajo I: Microempresas y Pequeñas y Medianas Empresas" aprobó en su $30^{\circ}$ periodo de sesiones, celebrado entre el 12 y el 16 de marzo de 2018 en la ciudad de Nueva York, un proyecto de guía legislativa sobre los principios fundamentales de un registro de empresas (A/CN.9/WG.I/ WP.109). El propósito de este documento es ofrecer estatutos simplificados para que las MIPYME puedan insertarse en los sectores reglamentados de la economía, convenciendo a los Estados y a los empresarios que las ventajas de la formalización son superiores a su interés en operar en el sector extralegal de la economía.

Aprovechando la oportunidad que se plantea para reformar el sistema registral en sus aspectos orgánicos y funcionales, es aconsejable que se vuelva a dar coherencia a este mediante la división entre los registros de hechos que debe llevar el Servicio de Registro Civil e Identificación, porque inciden sobre la identidad, estado civil y capacidad de las personas, y aquellos que implican una previa calificación debido a la titularidad que está comprometida en la actuación que se requiere a cargo de un conservador. De esta forma, por ejemplo, el Registro de Vehículos Motorizados y el Registro de Prenda sin Desplazamiento pueden pasar a formar parte de un oficio nuevo y creado al efecto: el conservador de bienes muebles, con asiento en cada comuna o agrupación de 
comunas que correspondan al territorio jurisdiccional de un juzgado de letras ${ }^{6}$. $\mathrm{El}$ acceso general al respectivo registro se puede solucionar hoy mediante la intercomunicación de datos por vía electrónica. Por su parte, el Registro de Empresas y Sociedades debe volver a constituir una unidad con el Registro de Comercio, el cual debe ser reformulado de acuerdo con las actuales exigencias del tráfico ${ }^{7}$. La introducción de tecnologías de la información en las notarías y conservadores hace que el servicio resulte de fácil acceso y rápido para los interesados.

\section{Los fedatarios y el deseo de desnotarización}

El Proyecto prevé dos grandes pilares para reformar el sistema notarial: la creación del oficio de fedatario y la eliminación de ciertos trámites notariales. Sin embargo, los problemas que ambos buscan afrontar pueden ser resueltos a través del correcto empleo de medidas ya existentes o, cuando eso no sea posible, por otros expedientes que no supongan tantas externalidades negativas.

A diferencia de los notarios, que están ligados de modo indisoluble al descubrimiento del Nuevo Mundo y a la llegada del derecho, los fedatarios son una figura extraña a nuestro sistema jurídico y provienen de la práctica anglosajona, donde la idea de fe pública es un concepto ajeno ${ }^{8}$. De hecho, la figura proviene de una reforma introducida en 2015 en Ecuador (decreto ejecutivo $250546 / 2015)$, por la cual se permitió que los funcionarios públicos certificasen las copias que se les presentaban. Si bien su función es más reducida, ellos podrán autorizar todos los actos y contratos contenidos en instrumentos privados, sin quedar sujetos a las mismas responsabilidades y obligaciones que existen para los notarios, ni tener obligación de establecimiento (art. 401 ter del COT). El Proyecto solo prevé que los fedatarios fijen domicilio. Para los notarios, en cambio, el COT distingue entre le oficio y la oficina. No se trata de actos sin trascendencia, puesto que pertenecen a esa clase, por ejemplo, los contratos de arrendamiento, de promesa, de transferencia de vehículos motorizados, el otorgamiento de poderes para administrar cuentas corrientes o retirar fondos depositados en bancos, los mutuos, letras de cambio y pagarés, las compraventas de acciones, etcétera.

En realidad, el problema que se pretende resolver tiene que ver con la cobertura que proporcionan las notarías y con el costo que sus trámites significan para los usuarios. Pero el remedio puede ser peor que la enfermedad, porque las soluciones propuestas ponen en riesgo la fe pública y, aun, la manera en

\footnotetext{
${ }^{6}$ En España, el real decreto 1828, de 3 de diciembre de 1999, dispuso la creación del Registro de Bienes Muebles, el cual tiene por objetivo la publicidad de la propiedad y de las cargas y gravámenes sobre esta clase de bienes, así como la publicidad de las condiciones generales de la contratación. Su funcionamiento comenzó el 23 de febrero de 2000.

${ }^{7}$ Zárate (2018), p. 166. Por su parte, Caballero (2017), p. 581, ha propuesto lo subsistencia de ambos registros, si bien previa modernización del Registro de Comercio.

${ }^{8}$ Bravo (1978), pp. 63-64.
} 
que el notariado ha estado organizado en el país, como un oficio público de extensión o auxilio de la función judicial. De hecho, Alfonso de Azevedo (1518-1592) enseñaba en sus conocidas explicaciones sobre el derecho español que el notario tiene un cometido exclusivo, porque nadie fuera de él puede confeccionar y escribir instrumentos y actos judiciales y extrajudiciales dando fe de ellos ${ }^{9}$. La creación de notarías es una facultad confiada al Presidente de la República (art. 400 del COT), la cual debe ser ejercida teniendo en cuenta las necesidades efectivas de un determinado lugar. El recurso a mediciones econométricas, como las que tiene a su disposición la Fiscalía Nacional Económica, puede resultar de utilidad; pero la cuestión no puede quedar confiada a meros parámetros económicos, sino que hay que tener en cuenta el bien común y la correcta administración de justicia. En las comunas donde no esté justificado el establecimiento de una notaría, la función de dar fe respecto de ciertos actos cotidianos puede quedar confiada al oficial del Registro Civil, como se ha dicho por indicación parlamentaria, y ya se hace respecto de ciertos actos (por ejemplo, los finiquitos laborales) o, incluso, al secretario municipal. Los aranceles cobrados por las notarías también están fijados por el Ministerio de Justicia (art. 54 de la Ley n. ${ }^{\circ} 16280$ y DS 587/1998, del Ministerio de Justicia), de manera que solo basta con supervisar que se cumplan y se las sancione en caso contrario.

Si se desea evitar que ciertos trámites supongan un pago para el interesado, la solución puede consistir en reformular el privilegio de pobreza y asociarlo con ciertos parámetros objetivos (por ejemplo, que se entienda concedido de pleno derecho a favor de las personas que reciben pensiones asistenciales, estén cesantes, tengan ficha de protección social o gocen de algún otro tipo de ayuda o subsidio estatal, y evitar que su concesión sea un trámite judicial) o, bien, en aumentar los trámites notariales exentos de cobro que menciona el art. 602 del COT, donde figuran algunos de los que hoy se quiere desnotarizar. Hay un proyecto de ley presentado sobre esta materia (Boletin $\mathrm{n} .^{0}$ 12761-07)

Cabe pensar, asimismo, en una nueva configuración de las notarías que permita un mayor dinamismo en su funcionamiento. Esto puede incluir el conferir más competencias (ahora con reconocimiento legal) a los oficiales de secretaría que los notarios "conceptúen preciso para el pronto y expedito ejercicio de sus funciones y el buen régimen de su oficina" (art. 504 del COT), los que pueden asumir aquellos trámites que se prevé traspasar a los fedatarios, bajo la responsabilidad de quien los ha contratado. Incluso, se puede concebir una reforma más radical, que suponga una reconfiguración de las notarías como oficios servidos por varios funcionarios, donde todos respondan solidariamente por los hechos u omisiones de los demás y de sus empleados (art. 38 de la Deontología y Reglas de Organización del Notariado). Todavía más innovador puede ser adoptar el modelo francés, como ha propuesto Gian Franco Rosso, que desde 1966 permite que los notarios ejerzan sus funciones

\footnotetext{
${ }^{9}$ Bravo (1978), p. 70.
} 
a través de sociedades constituidas a ese efecto, con posibilidad de contratar otros que ayuden al titular ${ }^{10}$.

Aunque el Proyecto ya lo preveía, el Ministerio de Justicia presentó una indicación para eliminar la intervención de un notario en 49 trámites que revisten distintas formas jurídicas (escritura pública, notificación, carta poder, declaración jurada y autorización de firma). Si la mirada es solo numérica, estos trámites representan el $20 \%$ de aquellos que se realizan en una notaría de acuerdo con el informe de la Fiscalía Nacional Económica. El problema reside en que el cómputo no se debe hacer de este modo, sino desde la perspectiva de los usuarios, vale decir, hay que preguntarse si los trámites que se quitan del ámbito notarial son representativos de aquellos que realiza una persona cuando concurre a una notaría. Si se atiende a la naturaleza de los trámites incluidos, cuyo destino final todavía está pendiente de decidir, la respuesta es negativa. La mayoría de los llamados "trámites de mesón" no sufren cambios con la indicación presentada y, en otros casos, la forma notarial no es la única posibilidad de perfeccionar el acto, habiendo varias opciones para hacerlo.

El principal contacto que tiene una persona con una notaría no es para celebrar esponsales, contratos de edición o notificar el retiro de una cooperativa. Se concurre a ella para realizar declaraciones juradas sobre hechos propios, como sucede con una cada vez más larga lista de certificados, o para solicitar el cotejo de fotocopias con los documentos originales. En el caso de 252 las declaraciones, muchas de ellas pueden ser certificadas por el Servicio de Registro Civil mediante un rápido cruce de la información que posee, como sucede con el hecho de que una persona es soltera (o viuda o divorciada) porque no tiene matrimonio o acuerdo de unión civil vigente, o está viva porque no consta que se haya inscrito su defunción. Por lo demás, el art. $4^{\circ}$ de la Ley n. ${ }^{\circ} 18101$ señala que los documentos privados que contengan declaraciones juradas unilaterales que se deban presentar a autoridades administrativas solo requerirán la individualización y firma de la persona que los suscribe, acompañada de su cédula de identidad, sin que sea necesaria autorización notarial.

En otros casos, los trámites que se eliminan tienen varias formas de realización, como ocurre con el reconocimiento de un hijo de filiación no matrimonial (art. 187 del $C C$ ). Un ejemplo puede ayudar a comprender cuál es el beneficio de que el acto se perfeccione por escritura pública, al menos, como una posibilidad entregada a las partes. El contrato de arrendamiento de todo o parte de un predio rústico se puede celebrar por escritura pública o por instrumento privado suscrito en presencia de dos testigos mayores de dieciocho años que también firman (art. $5^{\circ}$ del DL 993/1975). La alternativa se explica por la oponibilidad que permite la escritura pública inscrita respecto de los acreedores hipotecarios (art. 1962 del CC), dado que la hipoteca se extiende a todo aumento, mejora o inmueble por accesión que tenga la finca (arts. 2420 y $2421 \mathrm{del} C C$ ). Este resguardo es muy importante para asegurar la rentabilidad

\footnotetext{
${ }^{10}$ Rosso (2018).
} 
de la inversión que realiza el arrendatario de un predio agrícola, sobre todo pensando que esta clase de contratos son de largo plazo por el uso que se le dará al predio (por ejemplo, plantar un bosque para talar y comercializar su madera). Si se elimina la posibilidad de otorgar el contrato por escritura pública, el arrendatario quedará protegido respecto de las ventas o transferencias en la medida que subsista el ejemplar del contrato que lo beneficia (art. 10 del DL 993/1975), sin un medio de oponibilidad externo.

En suma, parece apropiado recordar que el primer escribano público que hubo en el país fue Luis de Cartagena (1513-1587), nombrado por el Cabildo de Santiago en 1541, tres semanas después de la creación de la ciudad ${ }^{11}$. La institución notarial es una de las más antiguas que hay en Chile y es misión de todos cuidarla como parte de nuestra tradición y patrimonio cultural. Esto no excluye que se deba introducir las reformas que sean necesarias para mejorar la prestación de este oficio público; pero ellas se han de hacer con prudencia y evitando comprometer la fe pública y abrir flancos de judicialización de actos que hoy se resuelven merced a un buen empleo de la justicia preventiva envuelta en la labor de estos auxiliares de la administración de justicia. Un ahorro mínimo de tiempo y dinero para los usuarios puede significar a la larga más problemas que beneficios. Por de pronto, hay que comenzar por abrir nuevas notarías donde sea necesario, como hacía el suspendido DS 1515/2017, del Ministerio de Justicia y redistribuir algunas de las existentes.

III. LAS CUESTIONES INSTITUCIONALES RELATIVAS A LOS OFICIO DE NOTARIO, CONSERVADOR Y ARCHIVERO

Corresponde analizar ahora las cuestiones orgánicas relativas al nombramiento, ejercicio del cargo y fiscalización del cargo de notario, conservador y archivero, especialmente en lo que se refiere a las funciones concretas que estos desempeñan en cuanto ministros de fe pública.

\section{El sistema de nombramiento propuesto}

Supuestamente, el objetivo perseguido por el Proyecto es reducir las barreras de entrada y la discrecionalidad en los nombramientos de notarios, conservadores y archiveros. Sin embargo, esa finalidad no se consigue y, además, se elimina la carrera funcionara que se podía desprender de ciertas normas hoy vigentes (en especial el art. 287 del COT).

Es verdad que el Proyecto regula el contenido del examen que deben rendir los candidatos, algo en lo que ya había avanzado la Corte Suprema mediante el auto acordado n. ${ }^{\circ}$ 184-2014, pero el resultado objetivo no condiciona la selección del postulante. Eso se debe a que se establecen dos instancias donde

${ }^{11}$ Bravo (1978), p. 68. 
cabe la discrecionalidad: una por parte de la Corte de Apelaciones respectiva al elaborar "una terna de entre aquellos candidatos que hayan obtenido alguno de los diez primeros puntajes en el concurso respectivo" [art. 287, letra e) del COT] y, otra por parte, del Consejo Resolutivo de Nombramiento de Notarios, Conservadores y Archiveros, que elige a una persona de esa terna [art. 287, letra f) del $C O T$ ]. Esto sin contar, por cierto, con la facultad que se le asigna a la Corporación Administrativa del Poder Judicial para fijar la ponderación y los criterios de selección de los postulantes en atención a la plaza que se busca proveer [art. 287, letra b) del COT]. En otras palabras, la calificación obtenida en el examen no determina que una persona sea elegida. Si el propósito es eliminar la discrecionalidad, lo natural es que sea el resultado del examen lo que condicione la posición que tendrá el oponente. Tampoco se ve la necesidad de crear el referido consejo resolutivo, que esté integrado por el ministro de Justicia y Derechos Humanos, un decano de una Facultad de Derecho proveniente del Consejo de Rectores y un miembro del Consejo de Alta Administración Pública, pues solo contribuye a aumentar la burocracia cuando pueden usarse los organismos ya existentes (como, por ejemplo, la Academia Judicial).

Un sistema más razonable supone modificar los requisitos objetivos para ser notario, conservador y archivero (por ejemplo, exigiendo un mayor número de años de ejercicio de la profesión y la necesidad de haber aprobado el curso 254 de derecho notarial o registral que deberá impartir la Academia Judicial ${ }^{12}$ ) y contemplar una prueba de conocimientos preparada por la Academia Judicial (y no la Corporación Administrativa del Poder Judicial, cuya finalidad es muy distinta según establece el art. 506 del COT), la cual lo corregirá. La Corte de Apelaciones respectiva comprobará el cumplimiento de los requisitos respecto de la idoneidad de los candidatos y conformará una quina con las cinco mejores calificaciones, la que será remitida a la Corte Suprema para que provea el cargo. Si estos funcionarios son auxiliares de la administración de justicia, lo razonable es que su designación recaiga sobre dicha Corte. Incluso, se puede prescindir de la formación de una terna y nombrar para el cargo vacante a quien se encuentra primero en la lista de calificaciones, prosiguiendo con las siguientes vacantes en orden decreciente. Por cierto, esto exige conservar la carrera funcionaria que hoy existe en el art. 287 del COT y que debiese mejorarse, ya que su eliminación tendrá un impacto en el número y calidad de las postulaciones para cubrir oficios en zonas remotas o rurales, donde el movimiento de cada oficio es muy inferior al que puede haber en una capital provincial o regional. Un sistema basado en criterios objetivos debe privilegiar

${ }^{12}$ El Proyecto sólo prevé que el candidato tenga el título de abogado por al menos cinco años (artículo 463 bis COT) y que la Academia Judicial imparta unos cursos preparatorios de este examen, preferentemente en formato en línea, los que serán optativos para quienes rindan el examen (artículo 402 bis COT), de suerte que es posible que una persona postule sin haber tenido una formación específica en derecho notarial o registral. 
que el nombramiento dependa exclusivamente de los méritos demostrados por el postulante, con carrera funcionaria y concursos a cargo de un organismo especializado (como la Academia Judicial), el cual, además, debería impartir los distintos cursos habilitantes para los cargos de conservador de bienes raíces, de comercio, de minas, de archivero judicial y de notario, de matrícula obligatoria.

Otro aspecto que llama la atención es que no se ve la razón por la cual se impide la permuta o traslado de los notarios, archiveros o conservadores (art. 310 II del COT), cuando ella sigue siendo posible para otros funcionarios judiciales (art. 310 del COT). Si no se quiere introducir una discriminación arbitraria, las opciones son dos: o, bien, se establece la misma prohibición para todos, exigiendo que se vuelva a concursar al nuevo cargo o, bien, se regula la permuta o el traslado bajo condiciones objetivas que impidan los abusos.

La sustitución del art. 287 del COT en los términos que señala el Proyecto elimina la carrera funcionaria (aunque imperfecta) que ordena a los notarios, conservadores y archiveros en tres categorías. Esto exige, por razones de coherencia y para asegurar la idoneidad de los candidatos, elevar el número de años de ejercicio de la profesión (como existe, por lo demás, para los abogados integrantes de las Cortes de Apelaciones y de la Corte Suprema) y hacer obligatoria la formación en derecho notarial o registral. Aunque el Proyecto recoge esto de forma parcial al señalar los requisitos de acceso de los candidatos (art. 463 bis del COT), el resto del sistema sacrifica la carrera funcionaria, la que, como ha quedado dicho, debe mantenerse y perfeccionarse.

En este sentido, hay que tener en cuenta que las categorías de la segunda serie del escalafón secundario están definidas por el territorio jurisdiccional donde se emplazan, las cuales vienen configuradas, a su vez, en razón al tamaño y complejidad de los distintos oficios que comprenden cada categoría. Esto hace que sea poco recomendable permitir el ingreso de un abogado externo al Poder Judicial a un oficio de la primera categoría, por la sencilla razón que otro funcionario del mismo escalafón y categoría, o de la inmediatamente inferior, por cierto estará en mejores condiciones para ejercer su cargo de una manera eficaz, por la mayor experiencia que tendría.

Un aspecto loable del Proyecto es la inclusión de los notarios, conservadores y archiveros dentro de los miembros del Poder Judicial que deben participar en las actividades anuales de perfeccionamiento que organiza la Academia Judicial (art. 15 de la Ley n. ${ }^{\circ}$ 19346).

\section{La cesación en el cargo}

$\mathrm{El}$ art. 495 bis del COT establece que todos los auxiliares de la administración de justicia cesan en sus cargos a los 75 años de edad. El Proyecto dispone, además, que para el caso de los notarios, conservadores y archiveros, ellos cesarán en sus cargos al cumplir veintiún años sirviendo el mismo oficio.

El límite de edad establecido en el Proyecto parece razonable y es coincidente con la edad prevista para la jubilación de los otros auxiliares de la 
administración de justicia (art. 495 bis del COT). Sin embargo, dicha limitación presenta reparos en cuanto a su constitucionalidad debido a que comporta una “discriminación por edad en la vejez"13 , la cual está prohibida por el art. $2^{\circ}$ de la Convención Interamericana Sobre la Protección de los Derechos Humanos de las Personas Mayores (art. $5^{\circ}$ II de la CPR), y también por el hecho de que el artículo tercero transitorio de la Ley n. ${ }^{\circ} 19390$ excluyó del límite de los 75 años a las personas que se encontraban ya sirviendo un oficio, de suerte que el cambio que se pretende con el Proyecto afecta el principio de confianza legítima y los derechos adquiridos (arts. 19, n. ${ }^{\circ} 14$ y 26 de la CPR). Se hace presente que, si bien el directorio de la Asociación de Notarios, Conservadores y Archiveros y la asamblea extraordinaria convocada para abordar este tema han acordado no oponerse a la derogación de la norma que mantiene el privilegio de los cargos vitalicios que conservan ciertos funcionarios, se trata de un punto que conviene tener en cuenta porque podría ser levantado en cualquier momento mediante un requerimiento al Tribunal Constitucional, sea por vía de control preventivo (art. $96, \mathrm{n}^{\circ} 3^{\circ}$ de la $\mathrm{CPR}$ ) o de inaplicabilidad por inconstitucionalidad (art. 96, n. ${ }^{\circ} 6^{\circ}$ de la CPR).

Por lo demás, esto se conecta con el acceso al cargo y la eliminación de la carrera funcionaria. Como se ha señalado, el Proyecto elimina esta última y mantiene, un cierto grado de discrecionalidad en los nombramientos, lo cual entraña el riesgo de permitir el absurdo que postulantes que se ubiquen entre 256 los mejores puntajes de sus concursos puedan no llegar a ascender de categoría, y que luego de veintiún años sirviendo un mismo oficio se vean forzados dejar sus cargos. Esto presenta varios reparos, el primero de los cuales tiene relación con las garantías constitucionales de igualdad ante la ley (art. 19, n. ${ }^{\circ}$ 2) y de igual distribución de cargas públicas (art. 19, n. ${ }^{\circ} 20$ ), pues no se ve por qué solo los notarios, conservadores y archiveros deban tener un límite de tiempo en el servicio del cargo y no así otros auxiliares de la administración de justicia $\mathrm{o}$, incluso, los jueces ${ }^{14}$. Por lo demás, no se establecen criterios que justifiquen el límite de veintiún años y no de otra cifra. Si se piensa que una persona puede postular al cargo con cinco años de ejercicio profesional como

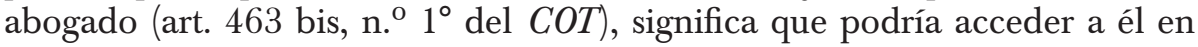
torno a los veintinueve o treinta de edad y servirlo por los próximos veintiún años, vale decir, hasta los cincuenta o cincuenta y un años. Esto significa que

${ }^{13}$ Ella existe frente a "cualquier distinción, exclusión o restricción basada en la edad que tenga como objetivo o efecto anular o restringir el reconocimiento, goce o ejercicio en igualdad de condiciones de los derechos humanos y libertades fundamentales en la esfera política, económica, social, cultural o en cualquier otra esfera de la vida pública y privada" (art. $2^{\circ}$ de la Convención Interamericana sobre la Protección de los Derechos Humanos de las Personas Mayores).

${ }^{14}$ La fijación de un plazo de expiración en el cargo por edad no compromete la garantía de inamovilidad de la que gozan los jueces. Ella supone que la continuidad de los jueces no depende de la voluntad de un órgano político (como el Congreso o el Poder Ejecutivo), salvo que cometa algún delito o incurra en mal desempeño, en cuyo caso corresponde la aplicación de los respectivos procedimientos judiciales o disciplinarios del caso (arts. 79 y 80 de la CPR). 
una persona, por el solo ministerio de una ley, pierde su trabajo en el momento en que ha alcanzado una consolidación y queda sin posibilidades de acceder al mercado laboral, precisamente porque su experiencia se ha desarrollado en el campo del que ha debido salir por un caprichoso límite temporal para el que no hay justificación razonable. Este límite de edad es un punto todavía más sensible debido a la eliminación de la carrera funcionaria, que debiese mejorarse y no suprimirse, y la discrecionalidad en el nombramiento de los cargos, que sigue existiendo de la manera antes apuntada.

Por lo demás, el notario, conservador o archivero que no ha tenido la fortuna de haber sido promovido durante los últimos veintiún años desde su actual oficio se tendrá que retirar irremediablemente al entrar en vigor el Proyecto ya promulgado. Esto lleva a preguntar por el número de oficios que quedarán sin su titular en forma inmediata, sin que se solucione el problema de vacancia mediante una norma transitoria.

\section{El sistema de fiscalización}

Una de las bases que inspira el Proyecto es el deseo de "perfeccionar el sistema de fiscalización" de los notarios, conservadores y archiveros. En la actualidad, ella se ejerce por las Cortes de Apelaciones a través de la figura de los ministros visitadores (art. 553 del COT) y por los jueces de letras del respectivo territorio (art. 534 del COT). En su reemplazo, el Proyecto propone un sistema doble, en parte público (a través de la Fiscalía Judicial) y en parte privado (a través de empresas independientes inscritas en el Registro de Empresas de Auditoría Externa que lleva la Comisión para el Mercado Financiero).

Pues bien, si lo que se busca es mejorar la fiscalización de estos auxiliares de la administración de justicia y, además, evitar el cobro de aranceles excesivos o demoras en la prestación del servicio, una decisión más razonable consiste en dividir de otro modo esta supervisión. Como ya proponía el proyecto presentado por el Ministerio de Justicia en 2013, el SERNAC resulta la entidad adecuada para controlar los cobros excesivos de arancel a los usuarios, los problemas de atención de público, los retrasos injustificados en la realización de trámites y el incumplimiento de los estándares tecnológicos requeridos para modernizar los oficios, sobre todo considerando que tiene una estructura orgánica adecuada y cuenta con experiencia en la materia. Los demás aspectos propiamente jurídicos pueden pasar a la Fiscalía Judicial debido a su complejidad.

Como fuere, tampoco es una decisión criticable la de acudir a los fiscales judiciales para establecer un sistema de fiscalización coherente de los notarios, conservadores y archiveros, como sí lo es la de recurrir a empresas de auditoría inscritas ante la Comisión del Mercado Financiero. Aquí se trata de prestar un servicio relacionado con la administración de justicia, el que no puede ser parametrizado bajo los estándares propios del mercado y de las sociedades con cotización bursátil. Un auxiliar de la administración de justicia no es una 
sociedad anónima con presencia en la Bolsa y, por consiguiente, no puede ser tratada de acuerdo con la disciplina prevista para ellas, que asume variables específicas de la incidencia que ella tiene en el mercado.

De perseverar en la decisión de concentrar esta función en la Fiscalía Judicial, el Proyecto debería aprovechar la oportunidad y avanzar por dar coherencia a la fiscalización y el sistema recursivo, haciendo recaer en las fiscalías judiciales dicho cometido, partiendo de la premisa que se trata de personas que pueden ejercen una eventual función jurisdiccional (arts. 215 y 463 del COT) y que cuentan con un jefe de servicio (el fiscal de la Corte Suprema) que puede impartir instrucciones, en forma verbal o por escrito, en los casos en que considere necesario seguir un procedimiento determinado para uniformar la acción de dicho ministerio (art. 350 del COT). Esto permitiría despejar las dudas respecto de la interpretación de la normativa aplicable y fijar criterios únicos de solución de las diversas controversias que se plantean al respecto (por ejemplo, la manera en que el testador debe acreditar "la circunstancia de hallarse en su entero juicio" de acuerdo con el art. 1016 del CC). Además, en lo tocante al ejercicio de sus funciones, los fiscales son independientes de los tribunales de justicia (art. 360 del COT), de suerte que se asegura la debida autonomía.

Desde este punto de vista, no se ve la necesidad de introducir un nuevo art. 353 bis del COT para incorporar la facultad de supervisión genérica de 258 los fiscales judiciales respecto de los notarios y conservadores, puesto que las funciones de tal oficio están señaladas en el art. 354 del COT. Como técnica legislativa, lo razonable es incluir la facultad de fiscalización a continuación de aquellas que hoy describe el art. 354 del COT (obrar, según la naturaleza del negocio, o como parte principal, o como tercero, o como auxiliares del juez), sea inmediatamente después de ellas, sea como inciso segundo, dejando la regulación concreta de la materia como art. 359 bis del COT, puesto que es ahí donde se termina de precisar el modo en que la Fiscalía Judicial interviene en los asuntos de su competencia. Hecha la fiscalización con la periodicidad que corresponda, que conviene sea anual, los fiscales informarán a las respectivas Cortes de Apelaciones con el fin de que apliquen las sanciones disciplinarias que sean del caso.

Dado que la fiscalización de estos auxiliares de la administración de justicia recaería en la Fiscalía Judicial, resulta razonable que sea el fiscal de la respectiva Corte de Apelaciones quien conozca del procedimiento judicial al que da lugar una negativa de inscripción (art. 18 del COT). Esto asegura la uniformidad y especialización de las decisiones. De esta forma, y puesto que la Fiscalía Judicial es jerárquica, el fiscal de la Corte Suprema quedaría como juez competente para conocer de la respectiva apelación, asegurando la unidad de criterio y la unificación jurisprudencial que se puede lograr por medio de las instrucciones que dicte al efecto dicho fiscal, obrando de manera similar a como lo hace la Dirección General de los Registros y del Notariado en España. Para este fin, es necesario modificar el titulo IV del COT, para incluir el o los artículos que 
concedan competencia a los fiscales judiciales para funcionar como tribunales unipersonales ${ }^{15}$. La distribución de causas entre los fiscales, cuando haya más de uno, viene ya solucionada por la facultad que el art 58 del COT concede a la respectiva Corte de Apelaciones para reglar de la forma que estime más conveniente el ejercicio de sus funciones a fin de proveer un mejor servicio. Por último, sería del caso incluir un art. 362 bis del COT, donde se permita que las funciones del fiscal puedan ser delegadas en ciertos funcionarios adscritos a su oficio (art. 493 del COT).

Otra opción para revisar el procedimiento frente a las reclamaciones de los interesados cuando se ha rechazado una inscripción por parte de un Conservador (art. 18 del RRCBR), las que actualmente dan lugar a muy disímiles criterios debido a que la discusión se cierra con la decisión de cada Corte de Apelaciones, consiste en disponer las reglas del caso para propender a la formación de una jurisprudencia única y vinculante respecto de las controversias sobre calificación registral, dejando ese cometido en manos de la Corte Suprema como tribunal de apelación y tras un contencioso bilateral (art. 20 del RRCBR).

Este último aspecto es muy importante, porque permite garantizar los principios de legalidad y legitimación registral. Con ese fin, en el procedimiento recursivo se debe corregir el desequilibrio hoy existente a favor del requirente de la inscripción, puesto que tanto en el RRCBR (arts. 18 y 20) como en el $\mathrm{RRC}\left(\operatorname{art} .8^{\circ}\right)$ se prevé que solo este puede apelar si el Juzgado de Letras no le ha dado la razón. Dado que una modernización del sistema registral se ordena a la especialización en la resolución de las controversias registrales, resulta necesario que el Conservador tenga también la posibilidad de defender su dictamen, más todavía si se reforma el sistema de calificación registral en los términos que se indicará más adelante ${ }^{16}$.

\section{LA DIGITALIZACIÓN DE LOS REGISTROS CONSERVATORIOS \\ Y LA CREACIÓN DE UNA REPOSITORIO DIGITAL Y DE UN REGISTRO NACIONAL DE INTERDICCIONES A CARGO DEL SERVICIO DE REGISTRO CIVIL E IDENTIFICACIÓN}

Uno de los aspectos que presenta mayor novedad dentro del Proyecto es la competencia que otorga al Servicio de Registro Civil e Identificación para llevar un repositorio digital que se nutrirá con la información que a diario remitan los notarios, conservadores y archiveros (2) y el Registro Nacional de Interdicciones (3). Por cierto, esto parte de la modernización que se quiere introducir en la gestión de los registros conservatorios mediante su digitalización (1).

\footnotetext{
${ }^{15}$ De seguirse esta alternativa, lo natural sería incorporar dos artículos: un art. 51 bis del COT referido a la competencia del fiscal de una Corte de Apelaciones y un art. 52 bis del COT para la competencia del fiscal de la Corte Suprema.

${ }^{16}$ Véase infra, V.
} 


\section{La digitalización de los registros conservatorios}

Bajo el apartado de modernización del sistema registral, notarial y archivístico, el Mensaje del Proyecto señala que este pretende, entre otros aspectos:

"Crear un repositorio digital de carácter nacional de responsabilidad del Servicio de Registro Civil e Identificación, para el adecuado archivo y gestión de los documentos extendidos y protocolizados en las notarías y de las inscripciones efectuadas en los conservadores".

Un repositorio es el "lugar donde se guarda algo"17, por lo que, sumado al adjetivo 'digital', se debería entender que la función que aparece asignada al Servicio de Registro Civil e Identificación sería satisfecha por medio de la creación de un sistema de archivo electrónico de los documentos extendidos y protocolizados en las notarías y de las inscripciones conservatorias. Sin embargo, el mensaje agrega que, además de la función de archivo, le corresponde la "gestión" de dichos documentos digitales, cuyo sentido no es claro en el articulado del Proyecto, generando problemas de interpretación en lo que se refiere a las funciones que se asignan al Registro Civil, por una parte, y a los conservadores, por la otra, en referencia a la custodia y actualización de los registros propiamente tales.

260 Dado que la gestión hace referencia a la administración y organización de una actividad, no resulta evidente su contenido ni la forma en la que dicho Servicio la llevará a efectos. Lo anterior es especialmente problemático si se estima que es atribución de los oficiales del Registro Civil el "otorgar certificados o copias autorizadas de las inscripciones existentes en los registros a su cargo" (art. 33 n. ${ }^{\circ} 3^{\circ}$ de la Ley n..$^{\circ}$ 19477), los cuales deben contener "todas las inscripciones y subinscripciones que corresponda" (art. 20 de la Ley n. ${ }^{\circ} 4808$ ). De este modo, si la referencia a la gestión aludiría a tales posibilidades, ello importaría una duplicidad respecto de las funciones de los notarios y conservadores, sin indicación de prevalencia ni de justificación.

En cualquier caso, la finalidad de dicho repositorio se justificaría con el desafío estatal de digitalización, variando el modelo original donde el soporte registral se encuentra en papel, lo que, a juicio del Ejecutivo, genera costos en lo referente a la generación, reproducción y almacenamiento de documentos. De esta manera, considerando los avances voluntarios realizados por algunos oficios, se plantea establecer exigencias tecnológicas en el ejercicio de las funciones desarrolladas por parte de notarios, conservadores y archiveros, que permitan la implementación de un sistema informático de trámites notariales y registrales de acceso centralizado, faciliten la publicidad de información disponible, la elaboración y trámite de documentos que se suscriben y solicitan ante ellos, conocer el estado de trámites pendientes, iniciar tramites de manera

${ }^{17}$ Real Academia Española (2014), p. 1901. 
electrónica y la interoperabilidad con otros actores del sistema. Si bien lo anterior se puede evaluar de forma positiva, el Proyecto no toma en consideración las dificultades y costos que importa la digitalización de toda la documentación que dichos auxiliares de la administración de justicia poseen, en especial en el aquellos oficios que cuentan con más de un siglo de antigüedad ${ }^{18}$. De este modo, si se atiende a lo dispuesto en el artículo tercero transitorio del Proyecto, se establece un plazo de tres años contados desde la entrada en vigencia de la ley para la digitalización de toda la información referente a la historia de la propiedad raíz de los últimos treinta años que conste en los libros que fueren de su cargo, lo que, incluso, se asocia con la funcionalidad del folio real. La norma resulta llamativa porque no se explican las razones por las cuales se escoge ese periodo de digitalización (treinta años ${ }^{19}$ ), ni se especifica con claridad la documentación a ser digitalizada, la que solo refiere como "información referente a la historia de la propiedad raíz", además de no considerar las diferencias en cuanto a la magnitud y costos del trabajo que ello impone para los diversos conservadores de bienes raíces. En este sentido, esta clase de normas debería establecerse sobre la base de evidencia empírica y estudios proyectados que observen la realidad y las diferencias entre los citados oficios y, en todo caso, estableciendo una aplicación gradual.

Ahora bien, en lo que respecta a las modificaciones al RRCBR, este nuevo modelo se estructura por medio de la propuesta de sustitución de sus arts. $4^{\circ}$ y $5^{\circ}$ y la incorporación de un art. 5 bis, de los que se sigue el reconocimiento de los siguientes principios para alcanzar los fines antedichos:

\section{a) La digitalización y formato electrónico}

El Proyecto se estructura sobre la base de la digitalización, lo que se enuncia ya desde la sustitución del art. $4^{\circ}$ del RRCBR, referido al inventario circunstanciado de los registros, libros y papeles pertenecientes a cada oficio. La reforma planteada no elimina dicha obligación, vale decir, los inventarios deben seguir siendo llevados por cada Conservador, pero se precisa que deberán ser realizados en forma digital y que su cierre se ejecuta por medio de firma electrónica avanzada.

La formación de dicho inventario resulta llamativa si se tiene en consideración que, en paralelo, el Proyecto dispone de la confección de un repositorio

${ }^{18}$ El RRCBR fue promulgado el 24 de junio de 1857. Con posterioridad, un decreto supremo de 28 de agosto de 1858 dispuso que su vigencia comenzara el 1 de enero de 1859. Como fuere, esos oficios supusieron la absorción de las Contadurías de Hipotecas creadas merced a la real pragmática de 31 de enero de 1768 y reguladas en ese entonces por el Reglamento de 20 de mayo de 1848.

${ }^{19}$ Esto tiene que ver con la costumbre de los conservadores de confeccionar los certificados que emiten a partir de una revisión de los registros a su cargo por un lapso de treinta años. El origen de este plazo se encuentra en el art. $2511 C C$, que exigía una posesión de tres décadas para beneficiarse de la prescripción adquisitiva extraordinaria. Desde la Ley n. ${ }^{\circ} 16952$, el plazo es diez años. 
digital a cargo del Servicio de Registro Civil e Identificación. Lo anterior no solo redunda en una dualidad de instrumentos digitales, sino que no se aclara en el Proyecto la función que cumpliría cada uno de ellos. Más aún, como se expresará más adelante, cuando se indica que el Conservador deberá

"incorporar al repositorio digital que al efecto lleva el Servicio de Registro Civil e Identificación, dentro de las 24 horas siguientes a su materialización, las inscripciones, subinscripciones, cancelaciones y demás anotaciones que hubiere practicado" (art. 5 bis del RRCBR),

sin aclarar si dicha incorporación implica una desafectación de la gestión de los registros por parte del Conservador (lo que se soportaría en la alusión a la "gestión de las inscripciones" indicada en el Mensaje del Proyecto) o si se trata solo de una transmisión de datos para la obtención de un archivo general de alcance nacional. El peligro de la primera interpretación es que, si este es el propósito del legislador, lo enviado al Servicio de Registro Civil serán las matrices electrónicas de las inscripciones propiamente tales, lo que resulta por completo incompatible con lo dispuesto en el n. ${ }^{\circ} 2^{\circ}$ del art. $5^{\circ}$ bis del RRCBR, en los términos que se indicarán a continuación.

Ahora bien, en el nuevo art. $5^{\circ}$ bis propuesto, el punto anterior es desarrollado de modo más completo y se agrega que, para cumplir con sus funcio262 nes, los Conservadores deberán mantener la infraestructura, equipamiento e insumos que permitan:

i) Disponer de medios telemáticos para la emisión, transmisión, comunicación y recepción de información. Esta medida se refiere a la aplicación de las técnicas de la telecomunicación y de la informática a la transmisión de información computarizada, de manera que toda la información contenida en los libros llevados por el Conservador pueda ser requerida, transmitida, comunicada o recibida por medio de técnicas de enlace computacional, incluso de manera remota.

ii) Llevar los registros, índices, repertorios u otro tipo de libros que les competan de manera electrónica. Lo anterior supone que todos los libros a cargo del Conservador no seguirán llevándose en formato papel, sino solo por medio de registros electrónicos.

Como ya se indicó, este deber no se encuentra coordinado con aquel que se incorpora en el art. $5^{\circ}$ bis del RRCBR por parte del Proyecto, que impone la incorporación al repositorio digital que al efecto llevará el Servicio de Registro Civil e Identificación, dentro de las veinticuatro horas siguientes a su materialización, las inscripciones, subinscripciones, cancelaciones y demás anotaciones que hubiere practicado. Así, si la transmisión de las actuaciones al mentado repositorio implica una desafectación de las funciones registrales de los conservadores, también queda la duda sobre la forma en la que se confeccionarán los registros parciales a su cargo cuando estos estarán precisamente formados por 
las matrices electrónicas que serán enviadas al Registro Civil, como, a su vez, la forma en la que se practicarán las anotaciones y subsinscripciones respecto a tales matrices si estas ya no se encontrarán a su cargo por haberse desprendido de su gestión. Es verdad que respecto de un documento electrónico no existe distinción entre el original y las copias (como tampoco la hay desde el punto de vista jurídico con aquellas extraídas de manera análoga de un repertorio o libro físico según el art. 342, n. $^{\circ} 2^{\circ}$ del $C P C$ ), pero eso no elimina que la gestión de los Registros corresponda al Conservador.

En este sentido, si lo que se quiere indicar es que existirá un doble sistema de acceso a la documentación (por medio de cada oficio conservatorio y por medio del repositorio digital), lo anterior no resulta claro de la norma, surgiendo dudas, en razón de la redacción del Proyecto, respecto de las funciones que tendrán los Conservadores en lo referente a la gestión de los libros digitales. Además, si lo que se pretende es contar con un doble sistema de acceso a la documentación digital, no resultan claras las razones por las cuales dichas funciones se asignan al Servicio de Registro Civil, en lugar de fortalecer un modelo de conectividad de los diversos conservadores de bienes raíces, al modo en que se está llevando a cabo por medio por algunos de ellos a través de iniciativas de implementación tecnológica, tanto de hardware como de software, e interconexión electrónica ${ }^{20}$.

Fuera de lo dispuesto por el mencionado art. $4^{\circ}$ del RRCBR respecto al inventario, el medio electrónico es señalado como la forma de llevar el Repertorio (art. 21 del RRCBR), la incorporación de planos (arts. 31 y 39 del RRCBR), los registros parciales (art. 34 del RRCBR) y el folio real (art. 51 bis del RRCBR).

iii) Contar con sistemas electrónicos para el adecuado archivo, tramitación y gestión de las inscripciones efectuadas en el respectivo conservador. En complemento a lo anterior, y dado que los registros se estructuran sobre la base de las inscripciones que se deben practicar en los libros conservatorios, ahora digitales, se establece la necesidad de contar con sistemas adecuados para su realización. Así, al tiempo en que el art. $4^{\circ}, \mathrm{n} .{ }^{\circ} 1^{\circ}$ del RRCBR da cuenta de la necesidad de contar con medios telemáticos para su requerimiento, el art. $4^{\circ}, \mathrm{n}^{\circ}{ }^{\circ}{ }^{\circ} \mathrm{del} \mathrm{RRCBR}$ pone énfasis en la gestión, tramitación y archivo de las inscripciones.

Obsérvese que nada se señala respecto a las subinscripciones, cancelaciones y otras anotaciones, solo indicándose que deberán efectuarse de forma digital en virtud de lo dispuesto en el inc. $2^{\circ}$ del artículo tercero transitorio del Proyecto. $\mathrm{Al}$ efecto, este dispone:

${ }^{20}$ El plan de interconexión que se ha implementado entre algunos conservadores del país permite la consulta remota de los asientos registrales entre oficios, contando, además, con la aptitud para implementar la solicitud de requerimientos de inscripciones por vía electrónica. 
"Lo anterior, es sin perjuicio del deber de cada conservador de practicar digitalmente y mediante firma electrónica avanzada las inscripciones, subinscripciones, cancelaciones y demás anotaciones que realizare en sus registros, desde el primer día de vigencia de la presente ley”.

Sin embargo, nótese que aquí se plantea una inconsistencia temporal. La práctica de subinscripciones, cancelaciones y demás anotaciones conforme al sistema digital se debe efectuar desde el primer día de vigencia de la ley, vale decir, seis meses después de la publicación en el Diario Oficial del Reglamento señalado en el artículo quinto transitorio (artículo primero transitorio). Por el contrario, y como ya se mencionó, el artículo tercero transitorio establece un plazo de tres años contados desde la entrada en vigencia de la ley para la digitalización de toda la información referente a la historia de la propiedad raíz de los últimos treinta años. Esto implica que se mantendrán inscripciones registrales en formato físico, sea durante el cumplimiento del plazo de digitalización, sea porque no han existido modificaciones en la historia de la propiedad raíz durante los últimos treinta años. Con ello, no resulta posible que las subinscripciones, cancelaciones y otras anotaciones se efectúen solo en formato digital, puesto que ello provocaría un desajuste en el tracto registral y, en definitiva, en el estudio de la historia de la propiedad raíz. Lo anterior es obvio, ya que no es factible una actuación digital en aquello que aún se encuentra en soporte papel.

Ahora bien, el reemplazo del soporte papel por el electrónico supone la indicación de estándares tecnológicos que doten a la información de seguridad, integridad y disponibilidad, para lo cual la norma establece ciertos mínimos que distan de ser suficientes en materia de ciberseguridad $^{21}$. Aunque cabe agregar que, sin perjuicio de las indicaciones generales dispuestas por la ley, las características técnicas que, de manera específica, deberán cumplir los sistemas electrónicos de comunicación, archivo, conservación, certificación y consulta de los documentos, índices, libros y registros, así como las que aseguren la interconectividad del sistema registral con registros y órganos del Estado, serán determinados y actualizados por un reglamento dictado por el Ministerio de Justicia y Derechos Humanos y el Ministerio Secretaría General de la Presidencia ${ }^{22}$. De modo excepcional, el primero de esos ministerios podría fijar requisitos técnicos distintos para aquellos con-

${ }^{21}$ De acuerdo con su versión del año 2019, Chile ocupa el lugar n. ${ }^{\circ} 83$ en el ranking global de ciberseguridad elaborado por la International Telecommunications Union.

${ }^{22}$ De conformidad al art. $5^{\circ}$ transitorio del Proyecto: "los ministerios de Justicia y Derechos Humanos, Hacienda y Secretaría General de la Presidencia deberán dictar, en el plazo de un año contado desde la publicación de esta ley, el Reglamento que regulará las características técnicas que deberán cumplir los sistemas electrónicos de comunicación, documentos, libros y registros electrónicos, de notarios, conservadores y archiveros, y el Folio Real”. 
servadores que, por su situación geográfica, tamaño o recursos, estén imposibilitados de cumplir íntegramente estas obligaciones, cuestión que deberá ser debidamente acreditada por estos ${ }^{23}$.

Por ello, conforme a lo dispuesto en el Proyecto, se establecen estándares que permitan, al menos:

$1^{\circ}$ ) Inscribir electrónicamente los títulos e instrumentos mencionados en la ley a propósito de los registros que deban mantener los conservadores. Esto implica, como se dijo previamente, que los libros que deben llevar los conservadores solo se encontrarán disponibles en formato digital, puesto que ellos están compuestos por las inscripciones que la ley ordena o permite realizar a partir de los títulos e instrumentos pertinentes (art. $5^{\circ}$ bis, $n .^{\circ} 2^{\circ}$ del RRCBR). Esto no resulta recomendable y es preferible mantener la duplicidad de registros (papel y digital), como por lo demás ocurre con el Servicio de Registro Civil e Identificación, indicando que en caso de duda prima la inscripción física. De lo contrario se puede comprometer la fe pública producto del apresuramiento en la implementación de un sistema que requiere al menos de gradualidad y supervisión para garantizar la seguridad de la información digitalizada.

Cumple recordar que, en rigor, la inscripción conservatoria es el modo de adquirir el dominio de los inmuebles y derechos reales constituidos sobre ellos (art. 686 del CC). Como toda tradición, es un negocio jurídico bilateral que requiere la manifestación de la voluntad del transferente y del adquirente (art. 670 del $C C$ ). Por eso, para requerir la inscripción es necesario contar con un mandato otorgado por ambas partes (en general, a través de la cláusula usual "se faculta al portador...") o, bien, que ella sea suscrita directamente por ellas (art. 78 del RRCBR). El nuevo art. 78 del $\mathrm{RRCBR}$ propuesto elimina esta exigencia, quedando como una obligación del notario la remisión electrónica de las escrituras al conservador (nuevo art. 401, n. ${ }^{\circ} 13 \mathrm{del} C O T$ ), lo cual introduce un problema en el sistema de la propiedad raíz que no parece resuelto en el resto del Proyecto.

Ello es enunciado luego en el mismo art. $5^{\circ}$ bis del RRCBR, al disponer que los estándares mínimos exigidos deben implicar la conservación electrónica de los registros, libros, índices, o cualquier

${ }^{23}$ Sin embargo, cabe preguntarse si acaso es seguro, en atención al estado de la tecnología vigente, el reemplazar todo el formato físico por el digital. $\mathrm{Al}$ respecto, hay que considerar que la pérdida de la información, como, a su vez, cualquier alteración de la misma, conduciría a la creación de un riesgo de grandes proporciones en atención a la pérdida de seguridad en el establecimiento y comprobación de los derechos reales (y sus efectos erga omnes) constituidos sobre bienes raíces. Dicha inseguridad no solo provocaría un aumento de la judicialización, sino, también, la incertidumbre respecto al modelo hipotecario vigente en nuestro país, produciendo un aumento de las tasas de interés, y, con ello, un encarecimiento en el crédito. 
otro documento que por ley deban llevar los Conservadores en el cumplimiento de sus funciones. De nuevo, surge la duda de la forma de compatibilizar estas normas con aquellas que suponen la incorporación de las actuaciones registrales en el repositorio digital a cargo del Servicio de Registro Civil e Identificación.

$2^{\circ}$ ) Extender y otorgar electrónicamente las copias y certificados que de acuerdo con la ley deban entregar. Ello supone que las copias y certificados se extenderán en formato electrónico en lugar de físico, aunque no queda claro si se está frente a un modo único de otorgamiento. Lo anterior, puesto que el $\mathrm{n} .{ }^{0} 7 \mathrm{del}$ art. $5^{\circ}$ bis del RRCBR dispone:

"los certificados que de conformidad a la ley puedan otorgarse en soporte electrónico y que sean suscritos por los conservadores con firma electrónica avanzada, serán válidos de la misma manera y producirán los mismos efectos que los otorgados por escrito y en soporte de papel, gozando del carácter de instrumento público para todos los efectos legales, sin que sea aplicable a estos actos el inciso segundo del artículo $3^{\circ}$ de la Ley $\mathrm{N}^{\mathrm{o}}$ 19.799, sobre documentos electrónicos, firma electrónica y servicios de certificación de dicha firma".

Este carácter facultativo debería considerar, por ejemplo, la factibilidad técnica para la entrega de copias electrónicas, como ocurre con los planos.

$3^{\circ}$ Llevar a cabo comunicaciones, notificaciones e intercambio electrónico de información entre notarios, conservadores y otros organismos o instituciones, de conformidad con la ley. Ello se plantea desde la interoperabilidad del sistema, a la que se refiere de nuevo el art. $5^{\circ}$ bis, $n .^{\circ} 8$ del RRCBR, lo que no aparece resuelto de modo adecuado en cuanto a los demás organismos o instituciones, dado que el Proyecto no establece un modelo computacional único de comunicación. Para estos efectos, deberá esperarse la dictación del reglamento pertinente por parte del Ministerio de Justicia y Derechos Humanos y el Ministerio Secretaría General de la Presidencia, aunque desde ya es posible observar que una redacción que solo resulte obligatoria para los notarios, conservadores y archiveros, y no para todos los organismos del Estado, resulta problemática para lograr la pretendida interoperabilidad sobre la base de una estandarización del sistema computacional.

$4^{\circ}$ ) La integración y adscripción electrónica con registros y órganos del Estado. Esto supone un punto avanzado de interoperabilidad, en el que los registros conservatorios se encuentran ya integrados con otros registros estatales, sin mención de cuáles serán dichos registros ni de qué manera se deberá producir tal integración. Lo 
anterior, además del hecho de que no se establece un modelo computacional único de comunicación, por lo que otra vez deberá esperarse la dictación del reglamento pertinente por parte del Ministerio de Justicia y Derechos Humanos y el Ministerio Secretaría General de la Presidencia, lo que suscita iguales dudas que las expresadas en el punto anterior sobre qué ocurre si no se establece una estandarización universal del sistema computacional.

$\mathrm{Al}$ efecto, en el informe evacuado por la Corte Suprema se indicó:

"[...] ante la importancia de las características técnicas y los constantes desarrollos informáticos que se hacen por los distintos órganos del Estado, resulta necesario que la Corporación Administrativa del Poder Judicial forme parte de las instancias que definan los estándares técnicos a utilizar, especialmente para que los futuros desarrollos promuevan la neutralidad tecnológica y la compatibilidad entre los sistemas, evitando los sobre esfuerzos económicos y humanos necesarios para crear interconexiones entre sistemas nativamente incompatibles".

Lo anterior, que se menciona en el citado informe a propósito de la Corporación Administrativa del Poder Judicial, es predicable de cualquier otra entidad estatal con la que se pretende dicha interacción.

En cualquier caso, los dos puntos anteriores se enlazan con el estándar mínimo dispuesto en el art. $5^{\circ}$ bis del RRCBR, relativo a la incorporación al repositorio digital que al efecto llevará el Servicio de Registro Civil e Identificación, dentro de las veinticuatro horas siguientes a su materialización, de las inscripciones, subinscripciones, cancelaciones y demás anotaciones que hubiere practicado. Se hará referencia a este punto más adelante con mayor detalle $^{24}$.

$\left.5^{\circ}\right) \mathrm{El}$ acceso de manera remota al público, de la información de los registros electrónicos que este contenga. Lo que complementa la noción de accesibilidad digital general enunciada en el nuevo art. $5^{\circ}$ del RRCBR, al que se alude a continuación.

\section{b) La accesibilidad digital}

El Proyecto agrega esta noción en la sustitución del art. $5^{\circ}$ del RRCBR, que, reiterando la necesidad de mantener funcionarios suficientes para que los trabajos estén al corriente y en buen orden, incorpora el deber de mantener en forma permanente los oficios, computadores, terminales, sistemas informá-

${ }^{24}$ Véase infra, IV, 2. 
ticos y redes disponibles para que el público general pueda consultar de modo gratuito los repertorios y registros electrónicos, sin perjuicio de su acceso en línea o de manera remota.

Conforme a lo indicado en el nuevo art. $5^{\circ}$ bis, n. ${ }^{\circ} 6$ del RRCBR, en el sitio web del oficio del Conservador se podrá consultar de manera gratuita los índices de registros y las inscripciones practicadas, solicitar inscripciones y acceder al repositorio digital del Servicio de Registro Civil e Identificación (aunque la norma no lo indique, lo anterior supone la incorporación del enlace respectivo) $\mathrm{y}$ a las inscripciones completas en formato digital. Obsérvese que la gratuidad se refiere a la consulta de índices de registros y de las inscripciones practicadas, pero no a la solicitud de inscripciones ni a las inscripciones completas (aunque lo último es discutible en atención a la mala técnica de redacción de la norma), las cuales se cobran a partir de un arancel fijado por el Ministerio de Justicia y Derechos Humanos (DS 588, de 3 de diciembre de 1998).

A su vez, el punto resulta poco coordinado con la idea de que, dentro del plazo de veinticuatro horas, el Conservador deberá incorporar las actuaciones registrales en el Repositorio digital a cargo del Servicio de Registro Civil e Identificación. Con ello, de nuevo queda en evidencia la incompatibilidad normativa y la técnica de las reformas propuestas, hasta el punto de no dar claridad respecto a quién se encuentra a cargo de la gestión de los registros digitales, o si acaso la normativa pretende una duplicidad que, conforme a lo antes mencionado en el presente informe, parece innecesaria e injustificada.

Por su parte, la accesibilidad física se encuentra unida a un nuevo régimen de funcionamiento de los registros, reemplazando el funcionamiento obligatorio de 9.00 a 16.00 horas, por uno, por regla general, no inferior a cuatro horas, indicado en su sitio web y dependencias. Los conservadores deberán informar el horario específico de atención y, de manera previa, sus modificaciones, tanto a la Corporación Administrativa del Poder Judicial como al público general. El Conservador deberá estar presente, al menos, durante el horario de atención al público. Sin embargo, la Corte de Apelaciones respectiva podrá autorizar de forma fundada días y horarios de atención distintos para aquellos conservadores que, por su situación geográfica, tamaño o recursos, les sea demasiado gravoso cumplir con este mínimo. Dicha accesibilidad y su forma de operación se encuentra más detallada en el art. 5 bis del RRCBR, en el que se dispone el contenido de la información actualizada del funcionamiento de la oficina que debe ser incorporado en su sitio web (n. $\left.{ }^{\circ} 6\right)$.

Este nuevo modelo genera varios inconvenientes, siendo el primero de ellos la ausencia de un horario común de funcionamiento de los diversos conservadores. Lo anterior tiene especial relevancia, puesto que el Proyecto parecería dar la idea de una diferencia entre el horario de funcionamiento físico de la oficina conservatoria (en el mencionado horario) y la factibilidad técnica de solicitar actuaciones registrales por medio de la plataforma digital (en un régimen continuo de plena disponibilidad). Esto produce problemas en 
lo referente a la incorporación de las solicitudes en el Repertorio, puesto que este, conforme al nuevo texto proyectado del art. 21 del RRCBR,

"se cerrará diariamente, indicando el número de notaciones practicadas en el día, indicando el primer y último número de la serie, la fecha y la firma del Conservador".

Demás está decir que este repositorio será digital y cerrado por medio de firma electrónica avanzada.

De este modo, un formato abierto para la solicitud electrónica de actuaciones registrales supondrá que el Repertorio no puede ser cerrado, tomando en consideración el fin del horario de funcionamiento, dado que este no existirá ni estará vinculado con el que corresponde al horario físico de apertura de las oficinas. Se generará así una cuestión no resuelta en el texto del Proyecto respecto a la forma de incorporar estas solicitudes en el Repertorio para el caso de ser efectuadas fuera de un horario predispuesto, y, con ello, se terminan afectando los principios de prioridad registral y la certeza del cómputo de los plazos previstos en el Reglamento. Lo anterior aconseja mantener un horario de funcionamiento común para todos los conservadores, previamente conocido para el público y los notarios, que resulte coincidente entre la atención presencial y la disponibilidad para la solicitud de actuaciones registrales de manera telemática.

c) La seguridad técnica en el acceso

El nuevo art. $5^{\circ}$ del RRCBR agrega que se deberán asegurar las condiciones técnicas para que los funcionarios del Conservador se puedan desempeñar de modo correcto y los usuarios reciban una atención adecuada. Lo anterior, reflejado el énfasis de la digitalización que plantea el Proyecto, supone el mantenimiento y actualización de los computadores, terminales, sistemas informáticos y redes disponibles tanto para la realización de las funciones registrales por parte de los funcionarios como para asegurar la atención del público, sea en lo que se refiere al Registro, sea a la consulta. De esta manera, se agrega que los gastos asociados a los registros, servicios computacionales, equipos y, en general, cualquier otro costo operacional concerniente al mencionado oficio, serán de cargo del Conservador.

d) El resguardo de los datos personales

$\mathrm{El}$ art. $5^{\circ}$ bis del RRCBR culmina indicando que es deber de los conservadores contar con infraestructura, equipamiento e insumos que permitan garantizar el debido resguardo de los derechos de los titulares de datos personales, en conformidad con lo establecido en la Ley n.$^{\circ}$ 19628, sobre protección a la vida privada. Este aspecto plantea dudas respecto a lo referente al principio de acceso digital y público al que antes se ha hecho referencia, puesto que el 
régimen legal no establece limitaciones expresas al requerimiento de información, ni siquiera por parte de quienes no demuestran tener un legítimo interés en el acceso a la información.

Sobre el particular hay países, como sucede hoy con el nuestro, que garantizan el acceso a la información de la que se dispone en los registros conservatorios, sin restricción alguna, aunque bajo el supuesto general de que la obtención de dicha información supone un acceso físico a la documentación pertinente, si bien desde hace algún tiempo es posible solicitar copias o certificados de manera digital. En la legislación vigente, la limitación se encuentra prevista en el art. 49 del RRCBR, que dispone:

"en orden a la guarda de los Registros incumben a los Conservadores los mismos deberes y obligaciones que a los escribanos. Son, no obstante, esencialmente públicos todos ellos; por consiguiente, es permitido a cualquiera consultarlos en la misma oficina y tomar los apuntes que crea convenientes".

Sin embargo, tal limitación se desvanece en el Proyecto, al incorporarse una frase final que permitiría "consultarlos a distancia en la forma que determina esta ley y el reglamento a que hace alusión el artículo $5^{\circ}$ bis, inciso final".

Dado el contenido del Proyecto, poner toda la información del Conserva270 dor a disposición de los usuarios en Internet es algo que puede resultar atractivo, pero es riesgoso. Por una parte, permite que, simultáneamente, diversos usuarios in situ o a distancia puedan tener acceso a la información, sin trasladarse de un lugar a otro; y se permite un estudio de títulos previo y a distancia, antes de solicitar todos los certificados necesarios, evitando dobles o triples concurrencias a las oficinas del Conservador. No obstante, por otra parte, se facilita el acceso a información personal y privada de terceras personas, incluso para empresas que pueden convertir este insumo en su giro comercial. Lo anterior no solo puede implicar la conversión de dicha información en un insumo transable en el mercado, sino que, también, facilita la comisión de fraudes al tener acceso universal a información personal de toda persona cuya identificación aparece consignada en los registros conservatorios ${ }^{25}$. En este sentido, cabe tener en cuenta dos aspectos que el Proyecto no parece considerar. El primero de ellos es el de robos de información que se produce de forma periódica desde las bases de datos del Servicio de Registro Civil e Identificación, sin que se prevean en paralelo iniciativas para reformar la ciberseguridad en esa repartición. Por otra parte, las empresas que obtengan la licitación de dicho servicio para implementar los sistemas de digitalización

${ }^{25}$ Hay que recordar, asimismo, que dicha información no solo se refiere a la situación y titularidad de los bienes raíces, sino que, también, integra otros datos sensibles, como los referidos a interdicciones o situaciones judiciales de las personas y empresas (embargos, procedimientos concursales, etcétera). 
y transferencia de datos en la práctica operarán como un "metaconservador" o certificador universal, lo cual abre flancos en materia de libre competencia y protección de datos personales que no han merecido discusión.

De ahí que otros países, considerando la protección de datos de carácter personal, restrinjan el acceso a los registros por parte de cualquier tercero. Así, por ejemplo, el art. 221 de la Ley Hipotecaria española dispone: "Los Registros serán públicos para quienes tengan interés conocido en averiguar el estado de los bienes inmuebles o derechos reales inscritos". En consecuencia, una solución intermedia consiste en plantear algún tipo de filtro al acceso de esa información, que sea solicitado objetivamente al tiempo de plantearse el acceso.

$\mathrm{El}$ modelo proyectado por la reforma parece insuficiente en este aspecto. La mera remisión a los derechos de los titulares de datos personales supone esclarecer, primero, la alusión al contenido de estos últimos. Al efecto, el art. $2^{\circ}$, letra f) de la Ley n. ${ }^{\circ} 19628$, los define como los relativos a cualquier información concerniente a personas naturales, identificables o identificadas, lo que implica una referencia bastante amplia acerca del contenido de las actuaciones conservatorias. Luego, en lo que se refiere a los derechos de sus titulares, cabe destacar las continuas restricciones que efectúa la citada normativa cuando la información se encuentre en fuentes accesibles al público, definidas en el art. $2^{\circ}$, letra i de la citada ley como aquellos registros o recopilaciones de datos personales, públicos o privados, de acceso no restringido o reservado a los solicitantes, como es el caso que se propone en la reforma en comento. En este sentido, no resultan aplicables normas como las que restringen la utilización de los datos obtenidos de tales fuentes públicas (art. $9^{\circ}$ de la Ley n. ${ }^{\circ} 19628$ ).

En todo caso, se podría incluir una referencia en los arts. 49 del RRCBR y 401, n. $^{\circ} 9$ del COT respecto de que la posibilidad de consulta sea satisfecha por medio de la exhibición de los asientos registrales ya digitalizados, permitiendo la revisión simultánea de los registros y evitando la obstaculización en el funcionamiento interno de los oficios. Sin embargo, se considera que estos aspectos no deben quedar entregados a la potestad reglamentaria, en especial si se considera que, en virtud de la reforma constitucional contenida en la Ley n. ${ }^{\circ} 21096$, el art. 19, n. $^{\circ} 4$ de la CPR dispone que esta asegura a todas las personas

“el respeto y protección a la vida privada y a la honra de la persona y su familia, y, asimismo, la protección de sus datos personales. El tratamiento y protección de estos datos se efectuará en la forma y condiciones que determine la ley".

\section{El Repositorio digital a cargo del Servicio de Registro Civil e Identificación}

El artículo décimo primero del Proyecto crea un mal llamado "repositorio digital” a cargo del Servicio de Registro Civil e Identificación, sin mayores 
precisiones sobre su alcance y efectos. A partir de dicha norma cabe concluir que el mentado registro tiene las siguientes características:

a) Se trata de una suerte registro digital, lo que implica que su conformación, gestión y consulta solo puede ser efectuada por medios electrónicos. Conforme a lo anterior, la pretensión es el acceso remoto y por medios informáticos de los documentos que deben ser incorporados por notarios ${ }^{26}$, conservadores y archiveros ${ }^{27}$. En todo caso, las especificaciones técnicas que deberá cumplir el repositorio serán determinadas y actualizadas por un reglamento dictado por el Ministerio de Justicia y Derechos Humanos dentro de los seis meses siguientes a la publicación de la ley ${ }^{28}$.

b) Reviste el carácter de un registro de alcance nacional, que se endereza a generar un sistema unificado de consultas, con independencia al lugar de otorgamiento del acto o del registro en el que se haya practicado la correspondiente actuación registral. Por ello, la existencia, administración, mantención y plena operación del Repositorio digital se centralizará en el Servicio de Registro Civil e Identificación.

El cuestionamiento se produce aquí por la idoneidad del mentado Servicio para llevar este repositorio, en especial si se considera que las inscripciones, subinscripciones, cancelaciones y anotaciones registrales no tienen relación con aspectos relativos al estado civil de las personas o conectados con su identificación (registros de hechos), sino solo con los derechos patrimoniales sobre los bienes raíces, y, más todavía, que se trata de aspectos donde es necesaria no la mera constatación de un he-

${ }^{26}$ De conformidad con el nuevo art. 401, n. ${ }^{\circ} 13$ del COT, se agrega como deber de los notarios "incorporar al Repositorio digital del Servicio de Registro Civil e Identificación, las escrituras públicas e instrumentos que hubieren sido por él protocolizados o autorizados, dentro de las 24 horas siguientes a su extensión o protocolización”. Para tales efectos, el nuevo art. 409 bis del COT dispone: "Suscrita una escritura pública por todos sus otorgantes, autorizada y sellada conforme a la ley, el notario autorizante deberá digitalizar tal instrumento para proceder a insertarlo en los registros pertinentes y ser guardado en el Repositorio digital de escrituras públicas que lleva al efecto el Servicio de Registro Civil e Identificación”. Asimismo, el art. 415 III del COT agrega: "Al igual que con las escrituras públicas, el notario deberá digitalizar el documento protocolizado y guardarlo en el Repositorio digital que lleva al efecto el Servicio de Registro Civil e Identificación". Por último, el nuevo art. 430 VI del COT añade: "El notario incorporará diariamente, de manera digital y bajo firma electrónica avanzada, al Repositorio digital, las anotaciones que en el Repertorio se hubieren efectuado cada día”.

${ }^{27}$ A pesar de la mención contenida en el artículo undécimo del Proyecto, no hay referencia expresa en su articulado permanente sobre un deber de incorporación de información al Registro por parte de los archiveros. Al efecto, el nuevo art. 456 bis del COT efectúa una remisión al reformado art. 401 del COT, pero el n. ${ }^{\circ} 13$ de dicha norma no resulta aplicable, puesto que ella se refiere a la incorporación de escrituras públicas e instrumentos protocolizados o autorizados, las que no son funciones propias de los archiveros de conformidad a lo dispuesto en el art. 455 del COT.

${ }^{28}$ Obsérvese, en consecuencia, que no se trata del mismo reglamento que, conforme al art. $5^{\circ}$ transitorio del Proyecto, debe ser dictado en el plazo de un año contado desde la publicación de la ley. 
cho (por ejemplo, que alguien nació, contrajo matrimonio, se divorció o ha muerto), sino la calificación de la situación jurídica en cuestión (de ahí que el Registro de Propiedad sea un registro de derechos) ${ }^{29}$.

Además, si el problema a resolver se encuentra en la facilitación en el acceso a la información, lo anterior puede ser satisfecho por medio de la incorporación de la noción de intercomunicación entre los diversos conservadores, de manera que por medio de cualquiera de ellos sea posible acceder a la información disponible en otros oficios. Como ha quedado dicho, tal innovación ya se ha aplicado por parte de algunos conservadores a través de iniciativas de implementación tecnológica, tanto de hardware como de software, e interconexión electrónica, llevadas a cabo de manera voluntaria.

$\mathrm{Al}$ igual como ha ocurrido con otras reformas legislativas, que ha concedido nuevas atribuciones al Servicio de Registro Civil e Identificación en este sentido (por ejemplo, en lo referente al Registro Único de Prendas sin Desplazamiento creado por la disciplina sobre la materia sancionada por la Ley n. ${ }^{\circ} 20190$, o lo ocurrido con la Ley n. ${ }^{\circ} 19903$ respecto de las posesiones efectivas de las herencias abiertas en Chile), no existen claras razones por las cuales se encomienda a dicho servicio esta clase de funciones. Por el contrario, las dificultades y falencias que presentan esos registros, y también el Registro de Empresas y Sociedad a cargo del Ministerio de Economía, Fomento y Turismo, llevan a pensar en lo inconveniente de una remisión de más información cuyo destino no queda claro.

Se hace presente las cuestiones antes referidas sobre la incorporación de datos de carácter personal, dado que, a pesar de la referencia indirecta dada a la Ley n.$^{\circ} 19.628$, se trataría de un registro de acceso público, restringiendo el derecho de sus titulares en lo que respecta al uso de dicha información.

Adicionalmente, cabe observar que en el informe financiero que se acompaña el Proyecto, si bien se hace mención a los mayores gastos en los que debería incurrir el servicio en virtud de la implementación del Repositorio digital, del Archivo digital de poderes y del Registro nacional de interdicciones, el presupuesto asignado se refiere a gastos en materia de software y hardware. Sobre el particular, más allá de lo exiguo del presupuesto, llama la atención la ausencia de una mayor dotación de personal para estos efectos, lo que sí se advierte para la Fiscalía Nacional Económica, la Corporación Administrativa del Poder Judicial, la Secretaría Ejecutiva del Consejo del Ministerio de Justicia

\footnotetext{
${ }^{29}$ De acuerdo con el art. $3^{\circ}$ de la Ley n. ${ }^{\circ} 19477$, el cometido del Servicio del Registro Civil e Identificación es velar "por la constitución legal de la familia", siendo su "objeto principal registrar los actos y hechos vitales que determinen el estado civil de las personas y la identificación de las mismas".
} 
y Derechos Humanos y la Fiscalía Judicial. Los costos involucrados en este tipo de modificaciones son, por supuesto, más altos que aquellos que se describe en el informe financiero, que debió ser modificado durante la tramitación en la Cámara de Diputados ${ }^{30}$.

c) En rigor, la expresión 'repositorio' designa el lugar donde se guarda algo. En este caso, se trata de proveer el acceso a los documentos que deben incorporar los oficios de notarios, conservadores y archiveros, y que consisten en todos los documentos, escrituras públicas, inscripciones, instrumentos protocolizados, certificados y copias emitidos con firma electrónica avanzada.

Como antes se ha indicado, el art. 5 bis n. ${ }^{\circ} 4$ del RRCBR establece el deber del conservador de mantener la infraestructura, equipamiento e insumos necesarios para incorporar al Repositorio digital que al efecto lleva el Servicio de Registro Civil e Identificación, dentro de las veinticuatro horas siguientes a su materialización, las inscripciones, subinscripciones, cancelaciones y demás anotaciones que hubiere practicado.

Sobre este particular, cumple tener presente que la mención hace referencia a la incorporación de dichos actos al Repositorio digital, lo que implica que no se trata de una nueva inscripción. En otras palabras, el repositorio solo tendría una finalidad de facilitación y unificación de las consultas, pero en caso alguno reemplazaría los registros, inscripciones, subinscripciones, cancelaciones y demás anotaciones practicadas por el Conservador. Sin embargo, y como ya se ha explicado, la redacción de la norma resulta contradictoria en la medida en la que se ordena la incorporación de la inscripción misma, firmada electrónicamente por parte del Conservador, en el Repositorio digital del Registro Civil, lo que implica una desafectación de la gestión de los registros por parte de los conservadores.

Por otra parte, es atribución de los oficiales del Registro Civil el "otorgar certificados o copias autorizadas de las inscripciones existentes en los registros a su cargo" (art. 33 n. ${ }^{\circ} 3^{\circ}$ de la Ley n. ${ }^{\circ}$ 19477), las cuales deben contener "todas las inscripciones y subinscripciones que corresponda" (art. 20 de la Ley n. ${ }^{\circ}$ 4808). Esto significa que, aunque el Proyecto no lo diga con claridad (el artículo decimoprimero transitorio menciona los certificados como una de las clases de documentos que debe incorporarse en el Repositorio digital), habría dos organismos con competencia legal para dar certificados sobre las inscripciones

${ }^{30}$ Por lo demás, los costos de implementación del nuevo sistema registral son, en realidad, más altos que aquellos señalados por el gobierno, y así fue expuesto por el profesor Alejandro Barros, consultor internacional en materias de modernización del Estado e innovación pública, quien fuera invitado por el propio gobierno cuando se inició la tramitación del Proyecto en la Comisión de Legislación y Justicia el día 24 de octubre de 2018. 
registrales. Lo anterior tiene particular importancia en el caso de existir alguna inconsistencia entre los registros conservatorios y el repositorio, lo que podría devenir no solo de fallas del sistema (humanas o técnicas), sino, también, del incumplimiento del deber de incorporación por parte del Conservador o de la brecha de veinticuatro horas prevista en la norma antes indicada. Esto, por cierto, sin contar con los supuestos de dobles inscripciones o de interrupción del tracto registral, que no tiene solución en el Proyecto. Los registros conservatorios son esencialmente mutables en razón de la práctica de nuevas inscripciones, subinscripciones, cancelaciones y otras anotaciones, por lo que la posibilidad de certificación respecto a actuaciones que son llevadas a cabo por otra entidad resta certeza jurídica.

A su vez, el artículo undécimo del Proyecto refiere la incorporación de dichas inscripciones, subinscripciones, cancelaciones y demás anotaciones que hubiere practicado, lo que no otorga suficiente claridad sobre la información que se ha de suministrar por parte de los conservadores al Servicio de Registro Civil e Identificación. Al efecto, a diferencia de lo que ocurre respecto a las obligaciones asignadas a los notarios en los nuevos arts. 409 bis y 415 III del COT, la norma antes citada no señala con claridad en qué consiste la incorporación de la información al repositorio digital. De esto sigue que se puede entender que, en caso de inscripciones, son estas las que deberían ser transmitidas de forma electrónica; pero, en el caso de las demás anotaciones, no se indica si ellas deben ser transmitidas autónomamente o junto con la inscripción original a cuyo respecto se ha practicado una subinscripción, cancelación o anotación. Incluso más, cabe preguntarse cuáles son los "certificados" que el conservador debe remitir a fin de que el Servicio del Registro Civil los incorpore al Repositorio digital, puesto que ellos tiene relación con la información que consta en sus registros y no suponen la agregación de datos nuevos. Lo anterior se dificulta aún más si se interpreta que la incorporación de las inscripciones en el Repositorio digital implica su desafectación de las funciones registrales de los conservadores, en la medida en que no se observa cómo podrían llevarse a cabo las mentadas subinscripciones, cancelaciones y demás anotaciones respecto a actuaciones registrales previas que ya no se encuentran sujetas a la gestión de los conservadores.

Por su parte, el nuevo art. 21 del RRCBR dispone:

"el Conservador incorporará diariamente, de manera electrónica y bajo firma electrónica avanzada, al Repositorio digital las anotaciones que en el Repertorio se hubieren efectuado cada día".

Esta norma, paralela a la dispuesta en el nuevo art. 430 VI del COT respecto a los notarios, no indica que se refiera al Repositorio digital 
que debe ser llevado por el Servicio de Registro Civil e Identificación, lo que debe aclararse para fines de consistencia, pues bien puede referir (de hecho, es más razonable que así sea) a los registros digitales del propio conservador (art. $4^{\circ}$ bis del RRCBR). No obstante, como ya se ha explicado, la redacción del Proyecto plantea sendas dudas respecto a la responsabilidad de los registros si se entiende que, más que un mero repositorio, las funciones del Servicio de Registro Civil e Identificación se plantean desde la perspectiva de la gestión de las actuaciones registrales.

\section{El Registro Nacional de Interdicciones}

El Proyecto también crea un Registro Nacional de Interdicciones a cargo del Servicio de Registro Civil e Identificación. Conforme se indica en el Mensaje, este tiene por finalidad facilitar la verificación, en cualquier parte del territorio, de la capacidad de las partes que concurren a la celebración de un acto jurídico. Ello obedece al hecho de que, en la actualidad, los decretos de interdicción, provisoria o definitiva, y los decretos de rehabilitación del disipador y demente, son puestos en conocimiento de la población por medio de la correspondiente inscripción en el Registro de Interdictos y Prohibiciones del Conservador de Bienes Raíces (arts. 447 y 461 del $C C$ y 32 y 53, n. ${ }^{\circ} 3$ del RRCBR). Dicha

276 inscripción se debe efectuar en el departamento donde tenga su domicilio la persona sobre quien recae el decreto como, asimismo, en el departamento o departamentos en que estén situados los inmuebles que le pertenecieren (art. 56 del RRCBR).

En este sentido, el Proyecto dispone el reemplazo de las voces 'departamento' y 'departamentos', por 'comuna' o 'comunas', respectivamente, en el art. 56 del RRCBR, aspecto que no presentaba dudas merced a lo dispuesto en el art. 447 del COT, además de agregar que dichas inscripciones son sin perjuicio de la inscripción de interdicción ante el Servicio de Registro Civil e Identificación. La misma reforma se efectúa en el texto del art. 447 del $C C$, de manera que la publicidad de los decretos de interdicción provisoria o definitiva se establece por medio de:

i) la inscripción en el registro conservatorio;

ii) la inscripción en el Registro Nacional de Interdicciones del Servicio de Registro Civil e Identificación y

iii) la notificación al público por medio de tres avisos publicados en un diario de la comuna o de la capital de provincia o de la capital de la región, si en aquella no lo hubiere.

En todo caso, se debería haber modificado también el art. 447 II del $C C$, que refiere al contenido de la inscripción y notificación (solo expresivas de que tal individuo, designado por su nombre, apellido y domicilio, no tiene la libre administración de sus bienes), debiendo indicarse que esta alusión es aplicable a "las inscripciones" (en plural), para comprender la nueva inscripción en el 
Registro Nacional de Interdicciones. Lo anterior, a menos que el contenido de dicha inscripción sea diverso en virtud de lo que se indica enseguida.

De conformidad a lo dispuesto en el artículo décimo del Proyecto, se crea el mentado Registro Nacional de Interdicciones, a cargo del Servicio de Registro Civil e Identificación, en el cual se inscribirán los decretos judiciales de interdicción provisoria y definitiva, agregando el nombre del curador designado. Las características, menciones, forma de operación y de acceso al registro serán reguladas a través de un reglamento expedido a través del Ministerio de Justicia y Derechos Humanos. Dada la conformación de dicho registro, cabe preguntarse. Cuál es la utilidad real de los demás medios de publicidad contenidos en el art. 447 del $C C$, si se considera los costos y tiempos que ellos involucran. Sobre todo es dable indagar por qué, si se busca la modernización del sistema de publicidad, no se elimina la necesidad de practicar la inscripción en el Conservador de Bienes Raíces respectivo, exigencia que solo tiene una explicación histórica: al momento de la entrada en vigor del Código Civil, este registro era el único de carácter estatal (los matrimonios se registraban por entonces en los registros parroquiales de la Iglesia católica, que todavía gozan de valor de acuerdo con el art. $\left.305 \mathrm{del} C C^{31}\right)$. Llevar el registro de estas situaciones es más coherente con la función que el art. $3^{\circ}$ de la Ley n. ${ }^{\circ} 19447$ le asigna al Servicio de Registro Civil.

Sobre el particular, conviene detenerse en los siguientes puntos no considerados por el Proyecto:

a) La normativa solo hace referencia a los decretos judiciales de interdicción provisoria y definitiva, ignorando los casos en los que el nombramiento de un curador provisorio (aun sin interdicción) se puede obtener por medio de una certificación administrativa.

$\mathrm{Al}$ efecto, de conformidad a lo dispuesto en el art. 18 bis de la Ley n. ${ }^{\circ} 18600$, las personas naturales o jurídicas que se encuentren inscritas en el Registro Nacional de la Discapacidad y que tengan a su cargo personas con discapacidad mental, cualquiera sea su edad, serán curadores provisorios de los bienes de estos, por el solo ministerio de la ley, siempre que se cumplan los siguientes requisitos:

i) que se encuentren bajo su cuidado permanente, lo que se verifica $\left(1^{\circ}\right)$ cuando existe dependencia alimentaria, económica y educacional, diurna y nocturna o $\left(2^{\circ}\right)$ cuando dicha dependencia es parcial, vale decir, por jornada, siempre y cuando esta haya tenido lugar de manera continua e ininterrumpida, durante dos años a lo menos;

ii) que carezcan de curador o no se encuentren sometidos a patria potestad y

iii) que la persona natural llamada a desempeñarse como curador provisorio o, en su caso, los representantes legales de la persona

${ }^{31}$ Véase IrarRáZabal (2014). 
jurídica, no estén afectados por alguna de las incapacidades para ejercer tutela o curaduría que establece el párrafo $1^{\circ}$ del título XXX del libro I del Código Civil.

Si bien el citado art. 18 bis de la Ley n. ${ }^{\circ} 18600$ señala que, cuando las circunstancias antes mencionadas constaren en el Registro Nacional de la Discapacidad, bastará para acreditar la curaduría provisoria frente a terceros el certificado que expida el Servicio de Registro Civil e Identificación, la finalidad prevista para la creación del Registro Nacional de Interdicciones podría parecer mejor cumplido si, adicionalmente a dicha certificación, se incorpora esta hipótesis a dicho registro.

b) La nueva normativa solo hace referencia a los decretos judiciales de interdicción provisoria y definitiva, pero no a los decretos de rehabilitación del demente o del disipador, (arts. 455 y 468 del $C C$ ).

c) El Proyecto requiere la indicación del curador designado, lo que no se exige de modo expreso en el actual art. 56 del RRCBR, además de que no dispone cómo proceder en caso de que se deba nombrar un nuevo curador (por ejemplo, por incapacidad sobreviniente o remoción). Porque solo en el procedimiento especial del art. $4^{\circ}$ de la Ley n. ${ }^{\circ} 18600$ coinciden la declaración de interdicción y el nombramiento de curador, mientras que en el procedimiento común uno precede al otro (art. 843 del $C P C$ ), puesto que la interdicción (a diferencia del nombramiento de curador) es un procedimiento contencioso.

d) El tratamiento del mentado registro, como ocurre usualmente en el texto del Proyecto, es derivado en cuanto a sus características, menciones, forma de operación y de acceso al registro a un reglamento expedido a través del Ministerio de Justicia y Derechos Humanos. A diferencia de otros reglamentos indicados en el Proyecto, en este caso nada se indica sobre el plazo para su dictación, lo que tiene relevancia puesto que no se trata de una norma cuya entrada en vigencia dependa explícitamente de ello.

e) Por lo demás, todo el sistema de incapacidades previsto en el Código Civil debe ser adaptado a la Convención Internacional sobre Personas con Discapacidad, promulgada mediante el DS 201/2008, del Ministerio de Relaciones Exteriores, y la Convención Interamericana para la Eliminación de Todas las Formas de Discriminación contra las Personas con Discapacidad, vigente en el país merced al DS 201/2008, del Ministerio de Relaciones Exteriores. De lo contrario, el Proyecto resulta anacrónico e inconstitucional ${ }^{32}$.

${ }^{32}$ Véase Silva (2017) y Lathrop/Espejeo (2019). 


\section{LOS PRINCIPIOS REGISTRALES}

En términos generales, se reconocen como principios del sistema registral los siguientes: inscripción, publicidad, legitimación, fe pública, rogación, prioridad, tracto sucesivo, legalidad, consentimiento y especialidad ${ }^{33}$. Se trata de ciertas:

"reglas o ideas fundamentales íntimamente relacionadas unas con otras que sirven de base y orientación al sistema registral inmobiliario, y que contribuyen al funcionamiento y eficacia del Registro" 34 .

Para los efectos de esas notas, se profundizará en tres de ellos, como son los principios de prioridad registral, calificación registral y tracto sucesivo.

\section{El principio de prioridad registral}

El principio de prioridad registral supone que

"el acto registrable que primeramente ingresa en el registro se antepone con preferencia excluyente, o bien con superioridad de rango, a cualquier otro acto registrable que, siendo incompatible o perjudicial, no hubiere sido presentado al registro o la hubiere sido con posterioridad, aunque dicho acto fuese de fecha anterior" ${ }^{35}$.

En nuestro ordenamiento jurídico, dicho principio está recogido de modo parcial y, como indica Marco Antonio Sepúlveda Larroucau, "no aparece reglamentada con toda la nitidez deseable" 36 . Usualmente este se construye a partir del art. 17 del RRCBR, que dispone que la anotación del título en el Repertorio caducará a los dos meses si no se convirtiere en inscripción ${ }^{37}$. No obstante, en un primer momento la Corte Suprema entendió que la anotación en el Repertorio no confería preferencia sino una vez practicada la inscripción. Conforme a lo anterior, por ejemplo, la anotación de un embargo en el tiempo intermedio impediría la enajenación del predio, aun cuando esta solicitud se hubiese anotado antes en el Repertorio, en razón de la aplicación del art. 1464, n. $^{\circ} 3^{\circ}$ del $C C^{38}$. Esta posición, sin embargo, ha ido variando jurispruden-

\footnotetext{
${ }^{33}$ Espinoza (2005), p. 33.

${ }^{34}$ Sepúlveda (2014), pp. 44-45.

${ }^{35}$ Espinoza (2005), p. 35.

${ }^{36}$ Sepúlveda (2014), p. 285.

${ }^{37}$ Para un estudio sobre la recepción jurisprudencial y doctrinal sobre este principio, GoNZÁLEZ (2008), pp. 354-355.

${ }^{38}$ En este sentido se pronuncian las siguientes sentencias: $R D J$, tomo 17 , sec. $1^{\text {a }}$, p. 100 ; tomo 45, sec. $1^{\text {a }}$, p. 392; F.M., n. ${ }^{\circ}$ 392, p. 282; F.M., n. ${ }^{\circ} 322$, p. 579. Rioseco (1995), p. 21, también refiere a este punto, sosteniendo: "aparte de cautelar los derechos de terceros, se ajusta al alcance del artículo 17 del Reglamento, que atribuye preferencia retroactiva en sus efectos a la inscripción una vez efectuada, pero no antes".
} 
cialmente, para admitir una suerte de "bloqueo registral" durante el plazo de caducidad de la anotación preventiva, de modo que el derecho de preferencia conlleva una validez retroactiva a la fecha de incorporación en el mentado Repertorio, sin generar el problema de ilicitud del objeto mencionada en el ejemplo anterior ${ }^{39}$. En doctrina, esta posición ha sido apoyada, por ejemplo, por los profesores Domingo Hernández ${ }^{40}$ y Edmundo Rojas ${ }^{41}$.

Sobre este punto, el Proyecto no altera el contenido de los arts. 15, 16 y 17 del RRCBR. En este sentido, se mantienen las reglas que obligan al Conservador a anotar en el Repertorio el título que se le presentare para ser inscrito, a pesar del motivo que encontrare para hacer la inscripción sea en su concepto de efectos permanentes o transitorios y fáciles de subsanar, considerando que, en cualquier caso, tal anotación caducará a los dos meses de su fecha si no se convierte en inscripción; el hecho de que la anotación presuntiva antes indicada se convertirá en inscripción cuando se haga constar que se ha subsanado la causa que impedía la inscripción; y que, convertida la anotación en inscripción, surte esta todos sus efectos como tal desde la fecha de la anotación, sin perjuicio de cualesquier derecho que se haya inscrito en el intervalo de la una y la otra. Conservado el tenor de las reglas, conviene insistir en una redacción más clara que privilegie la prioridad registral en forma expresa, con precisión de sus efectos.

Ahora bien, aun cuando las citadas reglas no han sido objeto de modificación, eso sí ha ocurrido con aquellas que se refieren directamente al Repertorio, tratadas en el art. 21 y siguientes del RRCBR. Al efecto, se transforma este en un registro electrónico de ingresos diarios, en que se anotarán las actuaciones e inscripciones que se requieran ${ }^{42}$, bajo una serie anual y general de números. Por motivos de certeza, el Repertorio se cerrará a diario, indicando el número de anotaciones practicadas en el día, indicando el primer y último número de la serie, la fecha y la firma del Conservador (que, luego, se indica es una firma electrónica avanzada).

Para lo que aquí interesa, el nuevo art. 24 del RRCBR modifica el contenido de la anotación de los títulos y contiene elementos que permiten entender la forma en la que funciona el principio de prioridad registral, en especial en lo referente a la hora de presentación, la naturaleza de la inscripción requerida y el registro parcial en que, según el art. 32, debe hacerse la inscripción, y el

${ }^{39}$ Así, $R D J$, tomo 88 , sec. $1^{\text {a }}$, p. 46 y $R D J$, tomo 91 , sec. $1^{\text {a }}$, p. 30.

${ }^{40}$ HeRnándeZ (2003), pp. 297-298.

${ }^{41}$ Rojas (2003), p. 378.

${ }^{42}$ El reemplazo del art. 21 I del RRCBR es cuestionable en cuanto a su redacción. El texto original hacía referencia a la anotación de los títulos que se le presentaren. El proyectado, en cambio, menciona a las actuaciones e inscripciones que se le requieran. El problema es la extensión del concepto 'actuaciones', puesto que este podría incluir otras gestiones como la obtención de copias o certificaciones, la facción de anotaciones, entre otras. Lo anterior se oscurece al tiempo en que también se ordena la remisión electrónica de las anotaciones efectuadas a diario al Repositorio digital que llevará el Servicio de Registro Civil e Identificación. 
número que en él le corresponde. Asimismo, tiene relevancia la conservación del art. 27 del RRCBR, que designa que las anotaciones se deben efectuar en el Repertorio ${ }^{43}$ bajo una serie general de números siguiendo el orden de la presentación de los títulos, para lo cual tiene relevancia la hora de la presentación. Este punto tiene especial importancia si se atiende a que las solicitudes pueden ser realizadas por medios telemáticos (nuevo art. 5 bis, n. ${ }^{\circ} 6$ del RRCBR), y que en razón de lo dispuesto en el n. ${ }^{\circ} 11 \mathrm{del}$ art. $401 \mathrm{del}$ COT, los notarios estarán obligados a:

"remitir electrónicamente al conservador competente para su inscripción, copia de los títulos traslaticios de dominio o la constitución o modificación de cualquier otro derecho real respecto de inmuebles, así como la constitución, modificación o terminación de cualquier tipo de sociedad sujeta a registro, que consten por escritura pública suscrita $u$ otorgada ante él, en instrumento protocolizado o reducción a escritura pública, según corresponda, sin necesidad de intervención personal de los interesados, a menos que éstos manifiesten su voluntad en contrario o no cubran el costo de la inscripción al respectivo conservador. Del mismo modo, deberá remitir al conservador competente para su inscripción, copia de los títulos por él otorgados y que facultativamente sean inscribibles por el interesado, siempre que el compareciente así lo manifestare y cubra el costo de la respectiva inscripción”.

Como ya se ha indicado, el problema se presenta en el caso en que las solicitudes de inscripción telemática fuesen realizadas en horarios diversos a los de funcionamiento físico del Conservador (el que, además, será diferente para cada uno de ellos), en especial si se atiende al cierre diario del Repertorio mediante firma electrónica avanzada (nuevo art. 21 del RRCBR).

\section{La calificación registral y el principio de legalidad}

Entre los principios más difundidos de un registro inmobiliario está el que corresponde al "examen de legalidad", también denominado "calificación registral", cuya principal función es conceder al registrador atribuciones de control preventivo sobre:

i) la existencia y estado jurídico del derecho inscribible (con determinación de la validez y eficacia de los títulos que constituyen los antecedentes jurídicos para la inscripción) y

ii) la congruencia entre la descripción del predio en el título y los caracteres que presenta en la realidad.

${ }^{43}$ Aun cuando el texto del art. 27 del RRCBR debería reemplazar la voz 'libro' por la de 'registro', para mayor consistencia con el nuevo art. 21 del RRCBR. 
Como han indicado ciertos autores, analógicamente se trata de una suerte de

“jurisdicción de naturaleza voluntaria, tiene carácter preventivo y provisorio y su naturaleza es precaria, ya que una vez que se reclame de la actuación de un conservador, cesa su función y pasarán los antecedentes a conocimiento del tribunal competente para conocer de la reclamación" ${ }^{44}$.

Esto explica que el Conservador sea un auxiliar de la administración de justicia (art. 446 del COT).

El mentado control preventivo está integrado por un conjunto de precauciones para el ingreso de un derecho al registro y, luego, para sus sucesivos traspasos, permitiendo una revisión jurídica de mérito por parte del Conservador. El modelo de revisión previsto no alienta el establecimiento de criterios uniformes a lo largo del país, que contribuirá al aumento de certeza jurídica. El profesor Daniel Peñailillo ejemplifica lo anterior advirtiendo que las atribuciones del Conservador son limitadas por el RRCBR en cuanto al examen de los títulos que se le presentan a inscripción, lo que conduce a que puedan presentarse, por ejemplo, desajustes entre los datos del predio consignados en la inscripción y sus caracteres materiales (por la falta de atribuciones de control preventivo, de exigencia de un plano y de un catastro industrial general ${ }^{45}$.

282 La calificación registral es la actuación que el Conservador debe llevar a cabo con anterioridad a practicar una inscripción (art. 12 del RRCBR) o subinscripción (art. 90 del RRCBR) en los registros pertinentes. En el ordenamiento chileno, tal deber se encuentra previsto en el art. 13 del RRCBR, que dispone que el Conservador no podrá rehusar ni retardar las inscripciones de los títulos que al efecto se le presenten de conformidad al art. 12 del RRCBR, solo facultando su negativa cuando la inscripción "es en algún sentido legalmente inadmisible". Para tales efectos la norma menciona ciertos ejemplos, como la falta de autenticidad o no estar en papel competente la copia que se le presenta; el hecho de no estar situada en el departamento o no ser inmueble la cosa a la que se refiere; si no se ha dado al público el aviso prescrito en el art. 58; si es visible en el título algún vicio o defecto que lo anule de forma absoluta, o si no contiene las designaciones legales para la inscripción. Sin perjuicio de lo anterior, y como ya se indicó, ello no resta aplicación al principio de prioridad registral, que proviene de la anotación preventiva en el Repertorio, con la que se da inicio al proceso registral.

La calificación registral se encuentra prevista, asimismo, en el art. 14 del RRCBR, que dispone:

\footnotetext{
${ }^{44}$ Espinoza (2005), p. 36.

${ }^{45}$ Véase Peñallillo (2019), pp. 787 y 827.
} 
"si el dueño de un fundo lo vendiere sucesivamente a dos personas distintas, y después de inscrito por uno de los compradores apareciese el otro solicitando igual inscripción; o si un fundo apareciese vendido por persona que según el Registro no es su dueño o actual poseedor, el Conservador rehusará también la inscripción hasta que se le haga constar que judicialmente se ha puesto la pretensión en noticia de los interesados a quienes pueda perjudicar la anotación. Los fundamentos de toda negativa se expresarán con individualidad en el mismo título”.

Esta norma, que se pone en dos casos concretos de calificación (la venta sucesiva o la venta por parte de quien no aparece en el registro como dueño), podría ser omitida mediante una mejor redacción del art. 13 del RRCBR que describa de manera más comprensiva la función del Conservador.

La normativa continúa con la disposición de los trámites a los que se debe sujetar la negativa, en especial si la parte perjudicada decide oponerse a la misma. En primer término, el art. 25 del RRCBR dispone que, devolviendo el Conservador el título por alguna de las causas mencionadas en los arts. 13 y 14 del RRCBR, se expresará al margen del Repertorio el motivo de la devolución, dejando en blanco la quinta columna para designar el registro parcial en que debe inscribirse el título y darle el número que corresponda a la fecha en que de nuevo se le presente, en caso de ordenarse por el juez la inscripción, según lo prevenido en el art. 19 del RRCBR.

Para tales efectos, se debe tener presente que el art. 18 del RRCBR le permite ocurrir al juez de primera instancia del departamento, quien en vista de la solicitud y de los motivos expuestos por el Conservador, resolverá por escrito y sin más trámite lo que corresponda. Al efecto, en caso de estimar procedente la inscripción, el art. 19 del RRCBR dispone que, en el mandato para la efectiva práctica de la inscripción, el Conservador debe hacer mención en ella del decreto en virtud del cual se le hubiese ordenado; al tiempo que el art. 20 del RRCBR agrega que el decreto en que se niegue lugar a la inscripción es apelable en la forma ordinaria. A contrario sensu, si se da lugar a la inscripción por medio de decreto judicial, este no sería susceptible de apelación, por lo que el Conservador deberá proceder en los términos dispuestos en el art. 19 del RRCBR antes referidos.

Ahora bien, el Proyecto no incide mayormente en el sistema recursivo recién descrito. Al efecto, las reformas al art. 13 del RRCBR son solo de ajuste a la normativa vigente, como aquella que elimina la posibilidad de negativa por no venir la copia "en papel competente" o el reemplazo de la voz 'departamento' por 'comuna' en lo que se refiere al ámbito competencial del Conservador (cuestión hoy resuelta por el art. 447 del COT). Sí llama la atención la intercalación de la frase "o estas no son correctas", en la indicación de la posibilidad de negativa en los casos en los que el título contenga designaciones legales incorrectas (esto es, no solo en ausencia) para los efectos de la inscripción. Lo anterior, aun cuando se debe recordar que la lista de casos en los que procede la negativa son ejemplares, siendo la tipología general el 
que la inscripción no sea "en algún sentido legalmente admisible" (art. 13 del RRCBR), dando lugar a dudas de si la corrección se refiere a la ausencia de errores formales o a un análisis de fondo de dichas designaciones.

Resulta relevante, también, la incorporación de un nuevo texto al art. 13 I del RRCBR, papa disponer que "los fundamentos de toda negativa se expresarán detalladamente en el mismo título", lo que se debe leer en consonancia con lo dispuesto en el nuevo texto del art. 25 del RRCBR, que agrega:

"devolviendo el Conservador el título por alguna de las causas mencionadas en los artículos 13 y 14, se expresará en el Repertorio el motivo de la devolución".

Hay que suponer, aunque la normativa proyectada no haga referencias normativas, que la causal invocada se debe indicar de igual modo en el título devuelto y en el Repertorio. Lo anterior tiene importancia sea para efectos de que el interesado pueda subsanar el vicio indicado o, en su defecto, ejercite las acciones judiciales pertinentes. En el primer supuesto, se debe tener presente que:

"en caso de que la causa de la negativa a inscribir, pueda ser atribuida a un descuido o negligencia del notario que intervino en el acto, los costos para la parte que se susciten con el fin de rectificarlo, serán asumidos por dicho notario" (art. 13 II del RRCBR).

Este punto fue levantado por la Corte Suprema en su informe sobre el Proyecto, al señalar que la regla:

"llama a confusión, pues no queda claro si lo que hace la regla es reiterar la responsabilidad civil que al notario le asiste por el desempeño culpable de su función, o bien asume que dichos funcionarios no deben ser responsables por los daños que ocasionen por negligencia en cuanto excedan la restitución de los costos en que incurre el usuario que requiere de sus servicios".

Por su parte, en lo que se refiere al art. 18 del RRCBR, solo se produce una aclaración a propósito de la competencia del tribunal que debe conocer de la controversia, radicándola en el juez de letras competente correspondiente a la comuna donde se halla el inmueble, en lugar de la referencia al juez de primera instancia del departamento. Por su parte, en el art. 19 del RRCBR solo se aclara que el dictamen judicial no tiene el carácter de decreto, aun cuando no precisa su naturaleza particular (se hace referencia a ella solo como "resolución"), lo que se reitera en el art. 20 del RRCBR al tiempo de indicar que esta es apelable cuando se niegue lugar a la inscripción. Lo razonable es aprovechar la reforma para reforzar la calificación registral (por ejemplo, precisando que la nulidad puede ser absoluta o relativa, formal o sustancial o, incluso, que une 
cláusula es abusiva de acuerdo con la Ley n.$^{0}$ 19496), evitando la técnica de la indicación de una causal genérica con ciertos casos ejemplares, y mejorar el sistema recursivo, de manera de crear una jurisprudencia registral consistente $\mathrm{y}$ acorde con los principios que informan los procedimientos reformados que tienden hacia la uniformidad de criterios.

Llama la atención que se haya agregado una frase final en el art. 19 del RRCBR, que pretende que el Conservador no solo mencione la resolución pertinente al tiempo de practicarse la inscripción, sino que agregue copia de esta al final del registro correspondiente. Ello es llamativo puesto que, siguiendo las pretensiones del Proyecto, los registros tienen el carácter de electrónicos, por lo que no se entiende cómo podría cumplirse con dicha nueva exigencia legal.

En términos generales, un mejor modelo registral debería instar por la formulación de un plazo perentorio para la realización de esta calificación (como lo hay, por ejemplo, en el art. 44 del DL 2695/1979) ${ }^{46}$. No hay que olvidar que ley fija plazos de respuesta tanto para los tribunales con las resoluciones (por ejemplo, art. 162 del $C P C$ ) como para la Administración con los procedimientos administrativos (art. 24 de la Ley n. ${ }^{\circ}$ 19880). Además, debería existir una convergencia con otras normas registrales, como la dispuesta en el art. $8^{\circ} \mathrm{RRC}$, que utiliza criterios solo parcialmente coincidentes en lo que se refiere a la calificación registral, siendo necesario el establecimiento de una cierta unificación ${ }^{47}$. De hecho, en esa sede no existe en rigor una facultad de calificación registral, puesto que el Conservador de Comercio solo puede rechazar una inscripción en tres casos:

i) cuando el documento no corresponde a aquellos que deben ser inscritos de acuerdo con el art. $7^{\circ}$ del RRC;

ii) cuando este no ha sido extendido en el papel correspondiente, una exigencia que hoy no existe al haber desaparecido el papel sellado merced al DL 3475/1980 y

iii) cuando no se ha cumplido con presentar copia autorizada del documento que se pretende inscribir según exige el art. 18 del RRC.

No hay, por ende, un control de mérito del documento inscribible para determinar su eficacia, como ocurre respecto del Conservador de Bienes Raíces (art. 13 del RRCBR).

Lo anterior tiene particular importancia cuando se considera que la Corte Suprema ha interpretado el art. 13 del RRCBR de manera restrictiva. Así, por ejemplo, ha resuelto:

${ }^{46}$ Sepúlveda (2014), p. 210.

${ }^{47} \mathrm{El}$ art. $8^{\circ}$ del RRC dispone lo siguiente: "El Conservador inscribirá en el Registro los documentos que se le presenten, y en caso de resistencia, que no puede dimanar de otras causas que de no corresponder el documento a la nomenclatura que precede, de no estar extendido en papel competente o de no haberse cumplido lo ordenado por el artículo 18, el interesado puede ocurrir al juez de comercio, quien resolverá, con audiencia del Conservador, si debe o no practicarse la inscripción. En el caso afirmativo, la inscripción contendrá el decreto que la ha ordenado. El decreto denegativo es apelable en la forma ordinaria”. 
"De conformidad al artículo 13 del Reglamento del Conservador de Bienes Raíces las funciones de dicho auxiliar de la administración de justicia en la constitución de la propiedad inmueble son esencialmente pasivas y no está dentro de ellas el examinar la validez de los títulos que se le presenten para su inscripción, salvo que una norma especial lo autorice para ello" ${ }^{48}$.

Se previene la necesidad de contar con un modelo que ofrezca mayores certezas, distinguiendo aspectos formales (propios del título o de la falta de coherencia de su contenido con la realidad registral, en lo referente a la denominada "titulación auténtica"), con aspectos de fondo (relativos a las eventuales infracciones al ordenamiento sustantivo, en lo referido a la "calificación registral") ${ }^{49}$. En referencia a estos últimos, también es necesario dar una mayor uniformidad a los criterios seguidos por los diferentes registros conservatorios, lo que no puede ser logrado por medio del solo recurso a los tribunales de justicia que pueden, incluso, funcionar como tribunales de única instancia en caso de acogerse la solicitud de la parte interesada (art. 19 del RRCBR). En este sentido, la recomendación consiste en generar un modelo de atribución jerárquica en el que se disponga de facultades consultivas y resolutivas (además de las fiscalizadoras), sea por medio de la creación de una superintendencia de registros inmobiliarios, como propone el profesor Domingo Hernández ${ }^{50}$, 286 o por medio de la creación de una oficina del notariado y del registro similar a la existente en España al interior del Ministerio de Justicia, como ha propuesto la Asociación de Notarios y Conservadores de Chile según consta de las observaciones presentadas por Elías Mohor $^{51}$. Sin embargo, esto se debe conciliar con la reforma que propone el Proyecto respecto a las facultades fiscalizadoras del Poder Judicial, las que se asignan a los fiscales judiciales. Por ello, de mantenerse esta posición, se puede explorar la posibilidad de estructurar en torno a dicha Fiscalía un modelo que reúna, con una correcta dotación de personal especializado, las funciones consultivas, resolutivas y fiscalizadoras antes indicadas, considerando que ella se haya estructurada jerárquicamente con un jefe de servicio que es el fiscal de la Corte Suprema (art. 350 del COT).

Otra opción es separar las facultades fiscalizadoras, confiando al SERNAC aquellas referidas a los cobros excesivos respecto del arancel a usuarios fijado por el propio Ministerio, los problemas de atención de público, los retrasos injustificados en la realización de entrega de los trámites y el incumplimiento de los estándares tecnológicos requeridos para modernizar los oficios, como

\footnotetext{
${ }^{48}$ Excma. Corte Suprema, sentencia de 3 de enero de 2011, disponible en RDJ, tomo XCVIII, $2^{\text {a }}$ parte, sección $2^{\text {a }}$, p. 5 .

${ }^{49}$ Sepúlveda (2014), p. 205.

${ }^{50}$ Hernández (2003), p. 276 y ss.

${ }^{51}$ Mohor (2003), pp. 417-418.
} 
ya se proponía en el Proyecto ministerial de 2013. Los aspectos relativos a la disciplina notarial y registral pueden quedar confiados a la Fiscalía Judicial.

Cualquiera sea la opción que se elija para la fiscalización de los conservadores, resulta evidente que el organismo respectivo debería estar revestido de la facultad de dictar normas generales de carácter obligatorio para lograr la uniformidad de criterios en la calificación de los títulos ${ }^{52}$. Como ha señalado el profesor Domingo Hernández,

"la organización descentralizada de las oficinas del Conservador de Bienes Raíces, y su plena autonomía respecto del Poder Ejecutivo, han representado un impedimento entre nosotros para el desarrollo de una jurisprudencia especializada y uniforme en orden a la calificación de legalidad de los títulos, puesto que la parte perjudicada con la negativa del conservador debe ocurrir ante el juez de primera instancia de la comuna o agrupación de comunas en que el conservador ejerce sus funciones, quien resuelve 'sin más trámite' lo que corresponda, previo informe del conservador. La posibilidad de recurrir en vía administrativa ante una instancia de carácter especializado, permitiría al afectado resolver tales situaciones en un tiempo considerablemente menor, y con evidentes ventajas desde el punto de vista técnico, abriendo camino al desarrollo de una jurisprudencia administrativa unitaria, que a no dudarlo disminuiría el trabajo de la jurisdicción civil hoy competente en la materia. Tal vía de reclamación no obstaría, por cierto, a la opción de recurrir ante la jurisdicción judicial, contra lo resuelto por el órgano administrativo de control de los conservadores [...]"53.

Por cierto, esto debe ir conectado con la eliminación de la diferencia entre títulos que deben (art. 52 del RRCBR) y otros que pueden (art. 53 del RRCBR) inscribirse, de lo cual el Proyecto no se hace cargo. Si se quiere garantizar la función del registro, lo razonable es que solo figuren en el Conservador de Bienes Raíces aquellos títulos cuya inscripción sea obligatoria. Esto exige revisar el catálogo de los actualmente existentes. A su vez, y con el propósito de mejorar la publicidad registral, es conveniente incorporar la necesidad de inscribir los arrendamientos sobre predios urbanos y rústicos (art. 1962 del CC) y las servidumbres (art. 698 del CC).

\section{El principio de tracto sucesivo}

Conocido también como "principio de continuidad", el tracto sucesivo tiene por finalidad reflejar la existencia de una cadena de titularidades, de manera que la inscripción de un bien inmueble (o de un derecho real constituido sobre

\footnotetext{
${ }^{52}$ Resulta de interés los criterios que refiere GuZMán (2016).

${ }^{53}$ Hernández (2003), p. 180.
} 
un inmueble inscrito) indique quiénes han sido sus anteriores titulares y su actual titular, posibilitando la consistencia de la historia de la propiedad raíz. Como señala Domingo Hernández, este principio

"tiende a que la serie de asientos que respecto de una finca figuran en los Registros de la Propiedad estén debidamente encadenada, de suerte que cada acto de disposición o gravamen aparezca derivado de la voluntad del titular inscrito" ${ }^{54}$.

$\mathrm{Al}$ efecto, un problema no resuelto por el RRCBR es aquel que se produce en caso que se produzca una interrupción del tracto sucesivo, de modo tal que sea posible su regularización. Tampoco se ocupa de la materia la Ley n. ${ }^{\circ} 16665$, que solo contempla el mecanismo de reconstrucción de las inscripciones total o parcialmente destruidas. En todo caso, se trata de un supuesto que sí ha sido reconocido en otras órbitas, como en el artículo primero transitorio del Código de Aguas, permitiendo tal regularización "mediante la inscripción de los títulos correspondientes desde su actual propietario hasta llegar a la inscripción de la cual proceden". Asimismo, el citado artículo dispone la procedencia de un sistema de revisión de la negativa, el que, en todo caso, debería estar ajustado al procedimiento descrito para la calificación registral.

Algo similar ocurre cuando existen meros errores de hecho en los asientos registrales (tales como la referencia a la superficie predial, a los deslindes o roles de avalúo), no existiendo en el RRCBR procedimiento alguno para su rectificación, y tampoco en el Proyecto.

\section{EL ESTABLECIMIENTO DEL FOLIO REAL}

En términos comparados, y dependiente del modo en que se organizan los registros inmobiliarios, es usual que se distingan entre los sistemas de "folio real" y "folio personal" 55 . Sin perjuicio de las diversas variantes en que se presentan ambos modelos, los primeros se destacan por una ordenación conforme a la identificación de los inmuebles, al tiempo que los segundos lo hacen a partir de la singularización de sus propietarios, normalmente de forma alfabética y cronológica $^{56}$.

Los modelos construidos en torno al "folio personal", como el chileno, presentan ciertos problemas basales relacionados con la ausencia (o, al menos, un detrimento) de certeza jurídica, en tanto, aun cuando el objeto de registro es el inmueble, toda anotación se realiza poniendo el foco en la persona de su

${ }^{54}$ Hernández (2003), p. 90.

${ }^{55}$ Para un mayor desarrollo sobre este tema, GonZÁLez (2008), pp. 335-338.

${ }^{56}$ Destacando especialmente las bases del sistema francés, cfr. PEÑA (1963), p. 721 y ss. En el ámbito hispanoamericano, puede consultarse, en términos generales, a BARNES, STANFIELD \& Barthel (2000) y FueYo (1991) y (1973). 
titular. Con ello, la dispersión es un escenario más que posible, incrementando el riesgo de inscripciones incoherentes o paralelas, sin contar las dificultades prácticas que implica su búsqueda para fines de estudio en registros disgregados.

La alternativa, esto es, los modelos de "folio real", se construyen sobre la base de la inmatriculación del inmueble, conformando un registro único en el que se encontrará toda inscripción que incida en su dominio o en el establecimiento de derechos reales u otras limitaciones que recaigan sobre este ${ }^{57}$. Su ventaja se encuentra en la configuración de un sistema sobre la base del elemento que constituye el centro del registro, como es el predio. Por ello, suele indicarse que su confección a través de una hoja independiente respecto a cada predio permite obtener toda la información registral que incide en este por medio del análisis de un único documento, facilitando su acceso y disminuyendo los riesgos de inconsistencias o inscripciones paralelas.

El Proyecto se suma a la tendencia a caminar hacia un modelo de "folio real”, lo que queda evidenciado ya desde su Mensaje. Ahí se expresa:

“promoviendo la modernización del sistema registral, el presente pro yecto establece el deber de llevar el registro y la historia de los bienes raíces mediante un folio real, lo cual debiese reducir los costos asociados a la inscripción de los títulos en el conservador de bienes raíces y disminuir en general los tiempos asociados a todo el proceso".

Después el Mensaje agrega:

"El actual sistema registral se basa en inscripciones efectuadas de manera sucesiva, en orden cronológico según se solicite la inscripción de los actos, contratos o resoluciones judiciales que contengan la transferencia, transmisión o gravamen de un bien raíz. De esta manera las inscripciones efectuadas son registradas en libros, quedando los actos relativos a un bien raíz dispersos en los registros, sin que exista un orden sistematizado. Lo anterior, genera altos costos y demoras debido a la dificultad que genera el estudio de la historia de los inmuebles, el cual constituye un aspecto necesario para la celebración de actos o contratos relativos a ese bien raíz. Para facilitar a los ciudadanos el acceso a la historia de un bien raíz y promover la transparencia de las operaciones, el proyecto propone la creación del sistema de folio real”.

Como fuere, hay que tener presente ciertas circunstancias relativas a la regulación del folio real en los términos previstos en el Proyecto:

\footnotetext{
${ }^{57}$ Para un estudio de diversos modelos basados en el "folio real", se pueden consultar los textos de Hernández (2003), pp. 308-309; Pau (1982); Martínez (2000); Friedmann (1935); CASAdo (1959a), (1959b) y (1959c).
} 


\section{La dualidad de registros}

La incorporación del folio real en los arts. 51 bis a quáter del RRCBR no elimina el modelo de registro hoy vigente, ofreciendo una duplicidad que no resulta justificada en el Mensaje. De hecho, el mismo objetivo que persigue el Proyecto se puede lograr mediante la aplicación de tecnologías de la información al actual sistema registral, de manera de asegurar la conexión de la información existente entre los distintos registros.

A tales efectos, se destaca que ya, desde la anotación en el Repertorio, el art. 24 del RRCBR anuncia tal duplicidad, dado que el . $^{\circ} 7$ refiere al número de folio real que corresponda al inmueble o el que se asigne al inmueble, si no lo tuviere; mientras que el n. ${ }^{\circ} 9$ hace alusión al registro parcial en que, según el art. 32 del $\mathrm{RRCBR}$, se debe hacer la inscripción, y el número que en él le corresponde.

Otro tanto ocurre con los registros parciales, considerando que el nuevo art. 41 del RRCBR agrega que estos contendrán un índice por orden alfabético, destinado a ingresar de forma separada el nombre completo de los otorgantes y la calidad en que actúan, así como el nombre completo de quienes representan, en caso de corresponder; la naturaleza de la inscripción; la comuna acompañada de la ubicación o nombre del bien raíz, según corresponda; la cita de la foja y número de la inscripción, y el número en el folio real que le corresponde. Lo mismo ocurre con el índice general aludido en el art. 43 del

290 RRCBR (que no es modificado por el Proyecto), por cuanto el nuevo art. 44 del RRCBR dispone que las partidas de ambos índices (de cada registro parcial y general), además del nombre de los otorgantes, enunciarán el folio real asignado al inmueble, la calle y comuna en que estuviere situado, la naturaleza del contrato o gravamen, la cita de la foja y número de la inscripción. El índice general citará también el registro parcial en que se halla la inscripción ${ }^{58}$.

Más evidente en cuanto a la duplicidad es la incorporación de una segunda oración en el art. 76 del RRCBR. En este sentido, además de mantener la necesaria anotación en cada inscripción, en el margen superior izquierdo, de la naturaleza del título y el número que le corresponda en el Repertorio, se agrega: "de la misma forma se anotará el número de folio real del inmueble al que se refiera la inscripción".

Lo mismo ocurre en el nuevo art. 78 del RRCBR, cuando agrega, entre las menciones que se deben incluir en las inscripciones de títulos de propiedad y de los demás derechos reales, el

"número de folio real que corresponda al inmueble o el que se asigne al inmueble si no lo tuviere. Si se tratare de fusiones o subdivisiones, de-

\footnotetext{
${ }^{58}$ Sobre este aspecto, se deberían simplificar los datos que deben estar contenidos en los índices parciales, considerando que su finalidad última es facilitar la búsqueda de información, por lo que cabe omitir aquellos datos que no son necesarios para el cumplimiento de este objetivo. Por su parte, se debe ponderar la necesidad real de mantener un índice general, toda vez que dicha información ya se encontraría disponible electrónicamente y, con ello, ya se facilita su búsqueda.
} 
berá además indicarse el folio padre y folios hijos, según corresponda" (n. $\left.{ }^{\circ} 3^{\circ}\right)$.

Algo parecido sucede en el nuevo art. 81 del RRCBR, que ordena hacer mención en las inscripciones hipotecarias a "la situación del inmueble hipotecado, su folio real y sus deslindes" (n. ${ }^{\circ} 3^{\circ}$ ).

Los principales problemas de dicha duplicidad son que, por una parte, no se advierte de qué manera ella contribuye a una de las finalidades indicadas en el Mensaje del Proyecto en lo que se refiere a reducir los costos asociados a la inscripción de los títulos en el Conservador de Bienes Raíces y disminuir en general los tiempos asociados a todo el proceso; $y$, por otra, que no se resuelven los problemas a los que podrían dar lugar eventuales inconsistencias entre uno y otros registros.

\section{El concepto del folio real}

De conformidad a lo previsto en el art. 51 bis del RRCBR, el Conservador de Bienes Raíces deberá mantener a su cargo, administrar y operar un sistema de inscripciones basado en el folio real. Por tal, el Proyecto entiende un soporte electrónico mediante el cual se debe consignar toda inscripción de bienes inmuebles y sus modificaciones mediante asientos sucesivos, que conforman en un solo formato el historial jurídico de los inmuebles. De lo anterior, se coligen tres elementos característicos del modelo propuesto por la reforma, como son:

i) su carácter electrónico (en línea con la digitalización de todos los demás libros que debe llevar el Conservador),

ii) la unidad (en el sentido que se propone la reunión de toda la información relativa a un inmueble) y

iii) su carácter sucesivo (que supone la identificación de un número correlativo de folio real).

En particular respecto a la idea de unidad, el folio real de un inmueble deberá contener al menos,

i) la individualización del inmueble, sus deslindes y ubicación;

ii) sus actuales propietarios;

iii) las hipotecas, gravámenes, prohibiciones y

iv) toda inscripción, subinscripciones, cancelación y anotación de que sea objeto de conformidad a lo que determine el reglamento al que hace referencia el art. 51 quáter del RRCBR.

Dicho reglamento debe ser expedido por el Ministerio de Justicia y Derechos Humanos y firmado también por el ministro de Hacienda y el ministro Secretario General de la Presidencia, determinando el formato, procedimientos y modalidades que deberá cumplir el soporte electrónico de gestión del folio real y la forma en que se deberá complementar, compatibilizar y digitalizar la información contenida en los registros y libros en soporte papel. De ahí que la regulación del folio real en el Proyecto sea tan lacónica y, en cierta medida, 
insuficiente para la comprensión de su funcionamiento a efectos de permitir su distinción con una mera certificación o resumen del contenido existente en los registros parciales. En todo caso, no queda claro si este reglamento es el mismo al que refiere el artículo quinto transitorio del Proyecto, que regulará las características técnicas que deberán cumplir los sistemas electrónicos de comunicación, documentos, libros y registros electrónicos, de notarios, conservadores y archiveros, y el folio real. Lo anterior es relevante, porque este último debe dictarse en el plazo de un año desde la publicación de la ley, y fijará, conforme al artículo primero transitorio, la entrada en vigencia de la ley dentro del plazo de seis meses desde su publicación.

\section{La información sucesiva consignada en el folio real}

Conforme al nuevo art. 51 I ter del RRCBR, en cierto sentido redundante con lo ya dispuesto en el nuevo art. 51 bis del RRCBR, en el folio real se deberán consignar de forma sucesiva la constitución, transferencia, extinción o modificación de los derechos reales constituidos sobre un inmueble, así como las prohibiciones, gravámenes y demás actuaciones que den cuenta los registros parciales, anotándose de modo correlativo en el mismo folio real a continuación de la singularización del inmueble respectivo.

La indicación de dicho contenido es imprecisa en cuanto no aclara si lo 292 que se requiere es una mera transcripción de las actuaciones que dan cuenta los registros parciales o si acaso se trata de una versión resumida de ellas. Lo anterior tiene relevancia en cuanto a lo indicado sobre la ausencia de normas que traten de las eventuales inconsistencias entre los registros parciales y el folio real.

\section{Las situaciones especiales relacionadas con la confección del folio real de un inmueble}

Los nuevos arts. 51 bis y 51 ter del RRCBR se refieren a tres situaciones especiales:

(a) Respecto a la solicitud de inscripción del título de un inmueble que a la fecha no tenga asignado un folio real, se ordena al Conservador confeccionar uno según esta modalidad. Lo anterior podría dar la impresión de que la facción del folio real se irá produciendo, en la práctica, en la medida en la que se vayan presentando solicitudes de inscripciones relativas a un inmueble, con independencia de la clase de título a la que ella se refiera. Esto significa que no existe un modelo de migración desde el inicio de la vigencia de la reforma, pero ello no se condice con el texto del artículo tercero transitorio, conforme al cual:

"Los conservadores de bienes raíces deberán digitalizar toda la información referente a la historia de la propiedad raíz de los últimos 
treinta años que conste en los libros que fueren de su cargo y a que hace referencia el artículo 51 bis de Reglamento del Registro Conservatorio de Bienes Raíces, dentro del plazo de tres años desde la entrada en vigencia de la presente ley, debiendo encontrarse plenamente operativo el registro electrónico de folio real para todos los inmuebles que correspondieren a sus respectivos oficios al finalizar dicho plazo".

En todo caso, este plazo parece irreal en razón de la magnitud del trabajo y los costos involucrados, sobre todo para oficios más pequeños.

Lo anterior, a mayor abundamiento de lo que pueda disponer el reglamento al que hace referencia el nuevo art. 51 quáter del RRC$\mathrm{BR}$, que, como ha quedado dicho, debe establecer la forma en que se deberá complementar, compatibilizar y digitalizar la información hoy contenida en los registros y libros en soporte papel.

(b) Respecto a la fusión de dos o más inmuebles, se deberá generar para el inmueble fusionado un nuevo folio real vinculado al de los inmuebles desde los que "acceden". Adviértase que la regla está dispuesta en lo referente al folio real, pero nada se indica sobre la forma de proceder en los registros parciales. En la práctica, se debería realizar una inscripción que dé cuenta de la fusión de los inmuebles, por razones de continuidad en el tracto registral, principio de especialidad y claridad del registro.

(c) Respecto a la división de un inmueble, se deberá generar un nuevo folio real para cada inmueble resultante, vinculados al del inmueble principal al que "acceden". También esta regla está dispuesta para el folio real, pero nada se indica sobre la forma de proceder en los registros parciales.

En los dos últimos casos, la voz 'acceden' es incorrecta, debiendo reemplazarse por una referencia al o a los inmuebles originales o del o de los que proceden. Lo anterior puesto que el término accesión tiene un contenido jurídico diverso (art. 21 del $C C$ ), relativo a un modo de adquirir los bienes (art. 588 del $C C$ ), definido como aquel por el cual el dueño de una cosa pasa a serlo de lo que ella produce, o de lo que se junta con ella (art. $643 \mathrm{del} C$ C). Asimismo, hay que considerar que, conforme al nuevo art. 78 del RRCBR, que versa sobre el contenido de las inscripciones de propiedad o de otros derechos reales, estos folios reciben el carácter de "hijo" o de "padre", según corresponda.

\section{CONCLUSIONES}

De los aspectos revisados en estas observaciones preliminares sobre el Proyecto que reforma el sistema notarial y registral en sus aspectos orgánicos y funcionales, resulta aconsejable que durante la tramitación del Proyecto se 
eliminen ciertos aspectos, se reformulen otros y se incluyan ciertas cuestiones relacionadas con el sistema registral que han sido omitidas.

1. Se debe eliminar:

(a) La facultad del Presidente de la República para fusionar cargos de notario y conservador, dado que se trata de oficios muy distintos entre sí.

(b) Las consideraciones ajenas al funcionamiento de un servicio que opera como un auxiliar de la administración de justicia y que, por tanto, no se debe ajustar solo a los criterios economicistas del mercado.

(c) La creación de un repositorio digital a cargo del Servicio de Registro Civil e Identificación, y, en su lugar, profundizar en un sistema que privilegie los siguientes aspectos:

i) mantener el formato papel, aun cuando se genere un respaldo electrónico descentralizado y actualizado de forma permanente sobre la base de cualquier modificación, actuación o solicitud registral;

ii) crear un folio electrónico para cada inmueble sin georreferencia;

iii) permitir la realización de procesos electrónicos para la práctica de las actuaciones registrales, en un horario aplicable a todos los conservadores y que sea coincidente con el del funcionamiento físico de sus oficios;

iv) permitir la emisión y otorgamiento de certificados electrónicos verificables mediante firma electrónica avanzada, de acuerdo con la normativa existente en la materia (incluyendo legislación, reglamentos y auto acordados dictados en la materia);

v) propiciar la interoperabilidad telemática entre los repositorios de los distintos oficios notariales y registrales, sin crear instancias burocráticas intermedias que encarezcan el sistema y pongan en riesgo su estabilidad y seguridad jurídica y

vi) permitir la consulta de los registros en la medida en la que se acredite un interés, sin perjuicio de la posibilidad de solicitar actuaciones registrales o retirar documentos pertinentes por medios digitales y telemáticos.

2. Se debe reformular:

(a) La compatibilidad entre conservador y archivero, que debe ser necesaria y no contingente.

(b) Los requisitos de acceso al cargo y el sistema de nombramiento, para hacer que este sea verdaderamente objetivo.

(c) La limitación de tiempo para el ejercicio del cargo.

(d) La carrera funcionaria, existente hoy de manera embrionaria, y que debe ser perfeccionada.

(e) La fiscalización y el sistema recursivo. 
3. Se debe agregar:

(a) Una regulación orgánica del sistema registral, no limitada solo al Conservador de Bienes Raíces, distinguiendo entre los registros de hechos (que corresponden al Servicio de Registro Civil de Identificación) y los registros de derechos (los cuales se entregan a un auxiliar de la administración de justicia, como es el Conservador, con facultades de calificación registral).

(b) Los efectos de la inscripción, por legitimación y fe pública registral.

(c) Los procedimientos de rectificación de títulos (cabidas, deslindes, numeración domiciliaria, rol de avalúos, etcétera).

(d) La prioridad registral, en especial cuando hay reclamo judicicial.

(e) El procedimiento para registrar la fusión y división de predios.

(f) Una mejor formulación de la calificación registral, uniformando los criterios existentes en el Reglamento del Registro Conservatorio de Bienes Raíces y el Reglamento del Registro de Comercio.

(g) El establecimiento de un plazo máximo para emitir un pronunciamiento en caso de que se requiera una inscripción.

\section{BiBLIOGRAFÍA}

Barnes, Grenville, David Stanfield \& Kevin Barthel (2000). "Land Registration Modernization in Developing Economies: A Discussion of the Main Problems in Central/Eastern Europe, Latin America, and the Caribbean”. URISA Journal. Vol. 12, n. ${ }^{\circ}$, Des Plaines.

Bravo Lira, Bernardino (1978). "La institución notarial en Chile. Notas sobre su origen y configuración jurídica”. Revista de Derecho de la Pontificia Universidad Católica de Valparaíso. N. ${ }^{\circ}$ 2. Valparaíso.

Caballero Germain, Guillermo (2017). "El sistema registral de comercio: de la publicidad a la fe pública mercantil", en Maximiliano Escobar SAavedra (ed.). Estudios de Derecho Comercial. Séptimas Jornadas de Derecho Comercial 2016, Santiago: Rubicón.

Casado Pallares, José (1959a). "El Registro de la propiedad en Australia actualmente". Revista Crítica de Derecho Inmobiliario. N. ${ }^{\circ}$ 368-9. Madrid.

Casado Pallares, José (1959b). "El Registro de la propiedad en Australia actualmente". Revista Crítica de Derecho Inmobiliario. N ${ }^{\circ} 370-1$, Madrid.

Casado Pallares, José (1959c). "El Registro de la propiedad en Australia actualmente". Revista Crítica de Derecho Inmobiliario. No 372-3, Madrid.

Espinoza VÁsquez, Evelyn (2005). El Conservador de Bienes Raíces. Santiago: Editorial Jurídica Congreso.

Friedmann S., Fernando (1935). "El régimen de la propiedad inmueble en Alemania y sus relaciones con el Derecho chileno". Revista de Derecho y Jurisprudencia. Tomo XxxII. Santiago. 
Fueyo Laneri, Fernando (1973). "El sistema legal de Chile”. Revista Crítica de Derecho Inmobiliario. $\mathrm{N}^{\circ}$ 495. Madrid.

Fueyo LANERI, Fernando (1991). "Particularismo del sistema legal de los Registros de la propiedad inmueble en Chile y juicios críticos al respecto", en Leyes Hipotecarias y Registrales de España. Fuentes y Evolución. Madrid: Colegio de Registradores de la Propiedad y Mercantiles de España, Centro de Estudios Hipotecarios. Tomo vi, vol. II-A.

González CAstillo, Joel (2008). "Reforma a los Conservadores de Bienes Raíces". Actualidad Jurídica. Año IX, n. ${ }^{\circ}$ 18, Santiago.

GuZMÁN BRITO, Alejandro (2016). La interpetación administrativa en el derecho chileno, Santiago, ThomsonReuters.

Hernández Emparanza, Domingo (2003). “Teoría general del Derecho registral inmobiliario", en FUndACIÓN FERNANDO FUEYO LANERI, Estudios sobre reformas al Código Civil y Código de Comercio, Cuarta Parte, Derecho Registral Inmobiliario. Santiago: Editorial Jurídica de Chile.

Irarrázabal Gomién, Andrés (2014). "Los inicios del Registro Civil de Chile: ¿ruptura o continuidad con las antiguas partidas eclesiásticas?". Revista de Estudios Histórico-Jurídicos. N. ${ }^{\circ}$ 36, Valparaíso.

Lathrop Gómez, Fabiola, Nicolás Espejo Yaksic (eds.) (2019). Discapacidad intelectual y derecho, Santiago, ThomsonReuters.

Martínez Velencoso, Luz María (2000). "La protección de los adquirentes de inmuebles en el Derecho alemán: Caracteres y efectos de la Vormer-Kung”. Revista Crítica de Derecho Inmobiliario. N. ${ }^{\circ}$ 657. Madrid.

Mohor Albornoz, Elías (2003). “Comentario de don Elías Mohor a la ponencia principal. Discusión habida durante el Seminario sobre Derecho Registral Inmobiliario chileno y comparado", en Fundación FERnANdo FuEYo LANERI, Estudios sobre reformas al Código Civil y Código de Comercio, Cuarta Parte, Derecho Registral Inmobiliario. Santiago: Editorial Jurídica de Chile.

PAU, Antonio (1982). "Panorama del sistema inmobiliario alemán”. Revista Crítica de Derecho Inmobiliario. N. ${ }^{\circ}$ 551. Madrid.

Peña y Bernaldo De Quiros, Manuel (1963). "El sistema registral francés". Revista Crítica de Derecho Inmobiliario. N. ${ }^{\circ}$ 426-427. Madrid.

Peñailillo ArÉvalo, Daniel (2019). Los bienes. La propiedady otros derechos reales, $2^{\mathrm{a}} \mathrm{ed}$. Santiago: ThomsonReuters.

Real Academia Española (2014). Diccionario de la legua española. $23^{\mathrm{a}}$ ed. Madrid: Espasa.

Rioseco ENRÍQUez, Emilio (1995). La posesión inscrita ante la jurisprudencia. Santiago: Editorial Jurídica de Chile.

Rojas García, Edmundo (2003). "Comentario crítico presentado por los Conservadores de Bienes Raíces señores Elías Mohor Albornoz, César Fuentes Vargas y Edmundo Rojas García: Capítulo tercero. Consideraciones en relación con la prioridad registral, la calificación de títulos, el procedimiento de reclamación y el organismo rector de notarios, conservadores y archiveros judiciales", en FundaCión FERnANDo Fueyo LANeri, Estudios sobre reformas al Código Civil y 
Código de Comercio, Cuarta Parte, Derecho Registral Inmobiliario. Santiago: Editorial Jurídica de Chile.

Rosso Elorriga, Gian Franco (2018). "Reforma a la institucionalidad notarial: hacia una nueva configuración jurídica de los establecimientos notariales". Cuadernos de Extensión Jurídica de la Universidad de los Andes. N. ${ }^{\circ}$ 30. Santiago.

Sepúlveda Larroucau, Marco Antonio (2014). Teoría general del Derecho registral inmobiliario. Santiago: Editorial Metropolitana.

Silva Barroilhet, Paula (2017). La capacidad jurídica de las personas con discapacidad intelectual, Santiago: ThomsonReuters.

ZÁrate GonZÁlez, Santiago (2018). "El sistema de registro de sociedades en Chile: ¿dos caras de una misma moneda?". Cuadernos de Extensión Jurídica de la Universidad de Los Andes. N. ${ }^{\circ}$ 30, Santiago.

\section{Jurisprudencia citada}

F.M. N. ${ }^{\circ} 322$, Santiago, 1985, p. 579.

F.M. N. ${ }^{\circ}$ 392, Santiago, 1991, p. 282.

$R D J$, tomo 17, sec. $1^{\text {a }}$, Santiago, 1920, p. 100.

$R D J$, tomo 45, sec. $1^{\text {a }}$, Santiago, 1948, p. 392.

$R D J$, tomo 88, sec. 1a, Santiago, 1991, p. 46

$R D J$, tomo 91, sec. $1^{\text {a }}$, Santiago, 1994, p. 30.

$R D J$, tomo $98,2^{\text {a }}$ parte, sec. $2^{\text {a }}$, Santiago, 2001, p. 5. 